Review Article

\title{
The Potential and Action Mechanism of Polyphenols in the Treatment of Liver Diseases
}

\author{
Sha Li, ${ }^{1}$ Hor Yue Tan $\mathbb{D}^{1},{ }^{1}$ Ning Wang $\mathbb{D}^{1,2}$ Fan Cheung, ${ }^{1}$ Ming Hong $\mathbb{D}^{1,3}$ and Yibin Feng $\mathbb{D}^{1,2}$ \\ ${ }^{1}$ School of Chinese Medicine, The University of Hong Kong, Pok Fu Lam, Hong Kong \\ ${ }^{2}$ Shenzhen Institute of Research and Innovation, Pok Fu Lam, The University of Hong Kong, Hong Kong \\ ${ }^{3}$ Institute of Clinical Pharmacology, Guangzhou University of Chinese Medicine, Guangzhou, China
}

Correspondence should be addressed to Yibin Feng; yfeng@hku.hk

Received 8 December 2017; Accepted 9 January 2018; Published 4 February 2018

Academic Editor: Sharad S. Singhal

Copyright (c) 2018 Sha Li et al. This is an open access article distributed under the Creative Commons Attribution License, which permits unrestricted use, distribution, and reproduction in any medium, provided the original work is properly cited.

Liver disease, involving a wide range of liver pathologies from fatty liver, hepatitis, and fibrosis to cirrhosis and hepatocellular carcinoma, is a serious health problem worldwide. In recent years, many natural foods and herbs with abundant phytochemicals have been proposed as health supplementation for patients with hepatic disorders. As an important category of phytochemicals, natural polyphenols have attracted increasing attention as potential agents for the prevention and treatment of liver diseases. The striking capacities in remitting oxidative stress, lipid metabolism, insulin resistance, and inflammation put polyphenols in the spotlight for the therapies of liver diseases. It has been reported that many polyphenols from a wide range of foods and herbs exert therapeutic effects on liver injuries via complicated mechanisms. Therefore, it is necessary to have a systematical review to sort out current researches to help better understand the potentials of polyphenols in liver diseases. In this review, we aim to summarize and update the existing evidence of natural polyphenols in the treatment of various liver diseases by in vitro, in vivo, and clinical studies, while special attention is paid to the action mechanisms.

\section{Introduction}

Liver diseases, containing a wide range of hepatic pathologies from steatosis, hepatitis, and cirrhosis to hepatocellular carcinoma (HCC), are leading causes of morbidity and mortality worldwide and have caused huge socioeconomic burdens [1]. The main etiologies of liver diseases are alcohol abuse, hepatitis virus infections, and metabolic syndrome [1]. The most important pathological processes of liver diseases are oxidative stress, lipid peroxidation, inflammation, and immune response disruption [2]. In response to hepatic injury, a cascade of molecular and cellular reactions would be generated with the aims of restraining damage, repairing damaged cells and tissues, defensing against further infection, and regeneration. Inflammation in the hepatic injury, the primary response, may initiate myofibroblast differentiation and activation that produce fibrous tissue and induce parenchymal cell proliferation, resulting in fibrosis and ultimately cirrhosis, the platform on which HCC and deadly hepatic failure develop [3]. As a matter of fact, most of the unresolved challenges in hepatology could be attributed to an imbalance of inflammatory processes $[4,5]$. On one hand, chronic hepatic inflammation promotes the progression of liver diseases, for example, from fatty liver to steatohepatitis. On the other hand, insufficient antimicrobial responses, inadequate tumor clearance, and/or suppression of antitumor immunity in the liver of patients with end-stage cirrhosis would lead to life-threatening bacterial infections and HCC development [4]. More importantly, oxidative stress, lipid peroxidation, and immune disorder have a close relationship with hepatic inflammation, which leads to an extremely complex network involved in the pathogenesis of liver diseases. The multiple pathways involved in the pathogenesis have provided extensive therapeutic targets for potential treatments [6].

Natural polyphenols are secondary metabolites of plants, which become noticeable as potential agents for prevention and treatment of several diseases, such as cancer, cardiovascular diseases, diabetes mellitus, aging, and neurodegenerative diseases [7]. They usually have 
subtle effects on multiple targets that eventually result in significant health benefits. Strikingly, polyphenols have been found to possess a variety of pharmacological effects on oxidative stress, lipid metabolism, insulin resistance, and inflammation, which are the most important pathological processes in the etiology of liver diseases [7, 8]. This puts polyphenols under spotlight for the therapy of liver diseases. In this review, we summarize the distribution of polyphenols in natural products to offer guidance for drug/health product development and dietary supplementation and focus on updating the existing animal and clinical trial results for the use of polyphenols in the treatment of liver diseases in different stages.

\section{Polyphenols in Natural Products}

Natural polyphenols is a large group of plant secondary metabolites ranging from small molecules to highly polymerized compounds, having at least one aromatic ring with one or more hydroxyl functional groups attached [9]. Based on chemical structures, natural polyphenols can be chemically divided into several classes, including flavonoids, phenolic acids, lignans, stilbenes, and other polyphenols $[9,10]$. Among them, flavonoids and phenolic acids account for about $60 \%$ and $30 \%$ of all natural polyphenols, respectively. Natural polyphenols are ubiquitously present in nature and particularly have been found in high quantities in many foods and plants, such as vegetables, fruits, cereals, spices, mushrooms, tea, microalgae, medical plants, wild fruits, and flowers [7]. The representative members and major dietary sources of each class are briefly summarized in Figure 1. A variety of factors, including but not limited to environmental condition, genotype, cultivar, harvest time, storage, and processing, could affect the levels of polyphenols in foods and plants, while species is still considered to be the primary factor resulting in different quantities in different products. By comparing the contents of polyphenols in a great deal of natural product through our studies and literature retrieval, several representative species with relatively high quantities of polyphenols in different kinds of natural products are listed in Table 1. In general, spices, medicinal plants, and fruit peels contain comparatively abundant polyphenols, which deserve special attention for further extraction, separation, and identification of phenolic compounds.

\section{The Potential and Mechanism of Action of Polyphenols in the Treatment of Liver Diseases}

3.1. Liver Injury Induced by Toxins and Drugs. Liver is a central organ responsible for the metabolism of drugs and toxic chemicals, and thus it is the primary target organ for various exogenous toxins, such as alcohol, organic solvents, heavy metals, and drugs [1]. As the main pathogenic mechanisms responsible for those toxic damages are oxidative stress, inflammation, dysfunction of cytochrome P450, and mitochondrial dysfunction [22], the application of flavonoids in attenuating liver injury induced by these toxins has been extensively studied. A wide spectrum of flavonoids showed promising therapeutic effects on liver injury induced by various toxins using animal models. The underlying mechanisms mainly involve enhancing antioxidative defense enzymes via mediating nuclear factor erythroid 2-related factor 2 (Nrf2)/cytochrome P450 2E1 (CYP2E1) expression, alleviating inflammation by inactivation of mitogenactivated protein kinase (MAPK)/nuclear factor kappaB $(\mathrm{NF}-\kappa \mathrm{B})$ signaling pathways and reducing apoptosis through regulating $\mathrm{B}$-cell lymphoma $2(\mathrm{Bcl}-2) /$ protein kinase $\mathrm{B}$ $(\mathrm{AKT}) /$ caspase expression.

Carbon tetrachloride- $\left(\mathrm{CCl}_{4^{-}}\right)$induced hepatotoxicity has been widely investigated in hepatology. Covalent binding of the $\mathrm{CCl}_{3}{ }^{*}$ radical to cell components inhibits lipoprotein secretion and thus initiates steatosis, whereas reaction with oxygen to form $\mathrm{CCl}_{3}-\mathrm{OO}^{*}$, introduces lipid peroxidation which in consequence results in apoptosis and cell death. Quercetin, a natural flavonoid with many beneficial effects, significantly protected liver from $\mathrm{CCl}_{4}$-induced injury via antioxidative stress and anti-inflammation. The underlying mechanism was ascribed to the inhibition of Toll-like receptor 2 (TLR2) and Toll-like receptor 4 (TLR4) activations and MAPK phosphorylation, leading to inactivation of NF- $\kappa \mathrm{B}$ and in turn reduced hepatic inflammatory cytokines [23]. Puerarin, a natural flavonoid that has been reported to have various medicinal properties, also remarkably attenuated $\mathrm{CCl}_{4}$-induced hepatotoxicity by reducing ROS production, renewing the antioxidant enzyme system and regulating expression of hepatic lipid biosynthesis and metabolism genes. It could restore total antioxidant capacity and GSH levels and significantly inhibit hyperlipidemia via regulating the expression of phosphorylated Jun $\mathrm{N}$-terminal kinases (JNK), phosphorylated c-Jun protein, and cholesterol 7ahydroxylase (CYP7A1) in the liver of mice receiving $\mathrm{CCl}_{4}$ [24]. Additionally, a marine polyphenol, dieckol, was found to be against $\mathrm{CCl}_{4}$-induced liver damage in mice via mediating apoptosis-regulating genes including downregulation of Bax and upregulation of Bcl-xl protein expressions [25]. In another study, isorhamnetin-3-O-galactoside, a flavonoid glycoside isolated from Artemisia capillaris Thunberg, showed protection on $\mathrm{CCl}_{4}$-induced hepatic injury through decreasing the level of phosphorylated c-JNK, extracellular signal-regulated kinase (ERK), and p38 MAPK. It diminished the increases of NF- $\kappa \mathrm{B}$ and $\mathrm{c}$-Jun nuclear translocation whereas enhanced the nuclear level of $\mathrm{Nrf} 2$, indicating its role in enhancing antioxidative defense system and reducing inflammation [26]. The flavonoid fraction from Rosa laevigata Michx fruit acted against $\mathrm{CCl}_{4}$-induced acute liver injury in mice through downregulating the expression of CYP2E1, inducible nitric oxide synthases (iNOS), NF- $\kappa \mathrm{B}$, $\mathrm{Bal}$, and Caspase- 3 , which was related to signaling pathways of oxidative stress, inflammation, and apoptosis [27].

Drug-induced liver injury is an important clinical issue. More than 900 drugs affect the liver directly or through mediating an immune response. Acetaminophen (AAP) is a classic example of a known intrinsic hepatotoxin at supertherapeutic dose. Baicalin, a well-known flavonoid of Scutellariae radix, can effectively relieve AAP-induced liver injury mainly through downregulating the ERK signaling pathway and its downstream effectors of inflammatory 


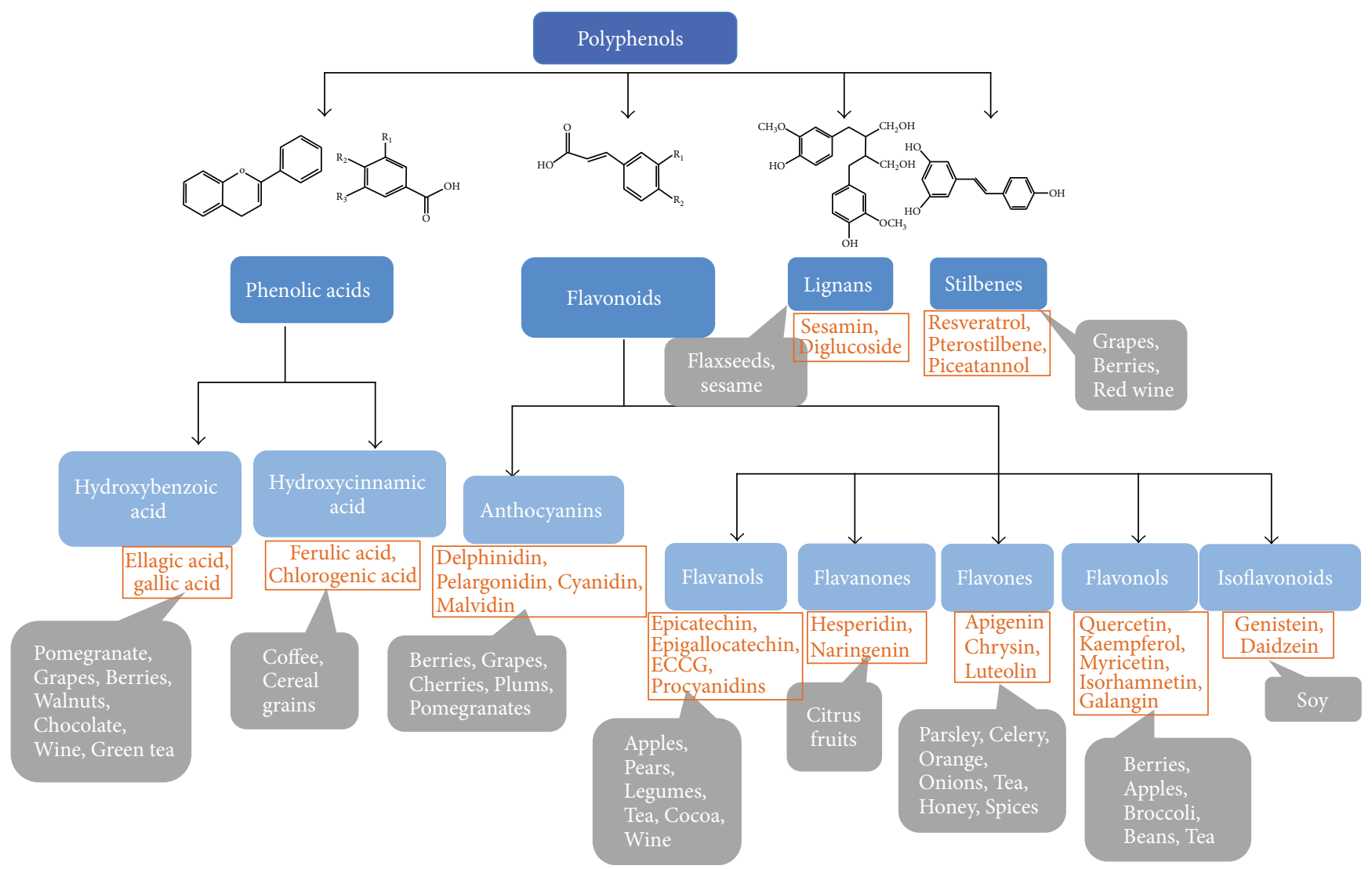

FIGURE 1: The classification and major dietary source of natural polyphenols. The four dark blue rectangles represent four major categories of polyphenols, while light blue rectangles are subcategories within the major classifications. The orange rectangles are representative polyphenols for each subcategory, and gray rectangles are major dietary sources for the corresponding representative polyphenols.

responses [28]. Polyphenol-enriched fraction from the leaves of Microcos paniculata L. showed hepatoprotective effect against AAP-induced liver damage via dual regulation of reactive oxygen species (ROS)/MAPKs/apoptosis axis and Nrf2-mediated antioxidant response [29]. A polyphenol extract of Hibiscus sabdariffa L. could ameliorate AAPinduced liver steatosis accompanied by a reduced hepatic expression of apoptosis-inducing factor (AIF), Bax, Bid, and p-JNK, suggesting it may exert hepatoprotective effect through attenuating the mitochondrial dysfunction [30].

The protective effects of several polyphenols on other toxins such as lipopolysaccharide (LPS) and thioacetamide (TAA) have also been extensively demonstrated, majorly via antioxidative stress and anti-inflammation. Here, we selected several studies that showed the effects of compounds with well-identified action mechanisms to discuss. Nobiletin, an O-methylated flavone, which is found in rich in the peel of citrus fruits, was able to protect the liver from LPS/D-galactosamine-induced injury through activating the Nrf2 antioxidant pathway and subsequent inhibiting NF- $\kappa$ B-mediated cytokine production [31]. Curcumin, a natural plant phenolic food additive, was found to significantly attenuate LPScaused liver failure. It decreased serum ALT, AST, and ALP levels, improved antioxidant enzyme levels, and inhibited activation of the mitogen-activated protein kinases/c-Jun $\mathrm{NH} 2$-terminal kinase (P38/JNK) cascade in the livers of rats with LPS administration. Furthermore, it reduced serum cytokines such as IL- 6 , IL- $1 \beta$, and tumor necrosis factor- $\alpha$ $(\mathrm{TNF}-\alpha)$ and improved liver apoptosis via suppression of phosphatidylinositol 3-kinase/protein kinase B (PI3K/AKT) signaling pathway and inhibition of cyclic AMP-responsive element-binding protein (CREB)/caspase expression. In addition, it regulated oxidative stress-associated signaling pathway in LPS-treated mice, as indicated by downregulated CYP2E1/Nrf2/ROS protein expression. Thus, curcumin may serve as a promising candidate to inhibit inflammation and apoptosis signaling for the treatment of endotoxemiainduced liver failure [32]. Silymarin, a mixture of flavonolignans extracted from Silybum marianum Gaertneri showed the ability to diminish hepatic lesions and inflammation caused by bisphenol A in mice [33]. Resveratrol, a naturally occurring polyphenol that possesses a variety of pharmacological activities, showed significant hepatoprotective effects on TAA-induced liver injury. It inhibited inflammation and oxidative stress by downregulating NF- $\kappa \mathrm{B}$ and CYP2E1 expression and enhanced apoptosis of necrotic hepatocytes through enhancing the activity of caspase-3 [34].

3.2. Alcoholic Liver Disease. Alcoholic liver disease (ALD) is one of the most important causes of liver-related death. Although the understanding about the progression and pathogenesis of ALD has been advanced, there are no universally 
TABLE 1: The representative species with relatively high quantities of polyphenols in foods and plants.

\begin{tabular}{|c|c|c|}
\hline Names & $\begin{array}{l}\text { Content of polyphenols } \\
\text { (mg GAE/g) }\end{array}$ & References \\
\hline \multicolumn{3}{|l|}{ Vegetables } \\
\hline Chinese toon bud & 23.27 & \multirow{5}{*}[11]{} \\
\hline Perilla leaf & 14.37 & \\
\hline Loosestrife & 13.13 & \\
\hline Soybean (green) & 12.39 & \\
\hline Pepper leaf & 12.14 & \\
\hline \multicolumn{3}{|l|}{ Fruits } \\
\hline Chinese date & 5.86 & \multirow{5}{*}[12]{} \\
\hline Sweetsop & 4.05 & \\
\hline Guava & 1.94 & \\
\hline Pomegranate & 1.47 & \\
\hline Chinese wampee & 1.16 & \\
\hline \multicolumn{3}{|l|}{ Cereals } \\
\hline Black rice & 9.47 & \multirow{5}{*}[13]{} \\
\hline Organic black rice & 6.95 & \\
\hline Purple rice & 4.85 & \\
\hline Buckwheat & 4.48 & \\
\hline Red rice & 4.43 & \\
\hline \multicolumn{3}{|l|}{ Spices } \\
\hline Clove & 143.8 & \multirow{5}{*}[14]{} \\
\hline Cinnamon stick & 119.0 & \\
\hline Oregano & 101.7 & \\
\hline Cinnamon & 63.4 & \\
\hline Sage & 53.2 & \\
\hline \multicolumn{3}{|l|}{ Mushrooms } \\
\hline Thelephora ganbajun zang & 44.84 & \multirow{5}{*}[15]{} \\
\hline Boletus edulis Bull & 14.15 & \\
\hline Volvariella volvacea Sing & 13.91 & \\
\hline Boletus regius Krombh & 10.17 & \\
\hline Suillus bovinus Kuntze & 9.19 & \\
\hline \multicolumn{3}{|l|}{ Tea } \\
\hline Fu'andabai & 223.7 & \multirow{5}{*}[16]{} \\
\hline Shuyong number 1 & 221.6 & \\
\hline Sichuanxiaoye & 215.0 & \\
\hline Shuyong number 2 & 215.0 & \\
\hline Menghaidayi & 215.0 & \\
\hline \multicolumn{3}{|l|}{ Microalgae } \\
\hline $\begin{array}{l}\text { Nostoc ellipsosporum } \\
\text { CCAP } 1453 / 17\end{array}$ & 60.35 & \multirow{5}{*}[17]{} \\
\hline $\begin{array}{l}\text { Chlorella protothecoides } \\
\text { number } 7\end{array}$ & 19.03 & \\
\hline $\begin{array}{l}\text { Chlorella pyrenoidosa } \\
\text { number } 3\end{array}$ & 17.24 & \\
\hline $\begin{array}{l}\text { Schizochytrium sp. } \\
\text { number } 5\end{array}$ & 15.94 & \\
\hline $\begin{array}{l}\text { Chlorella pyrenoidosa } \\
\text { number } 2\end{array}$ & 15.11 & \\
\hline
\end{tabular}

Table 1: Continued.

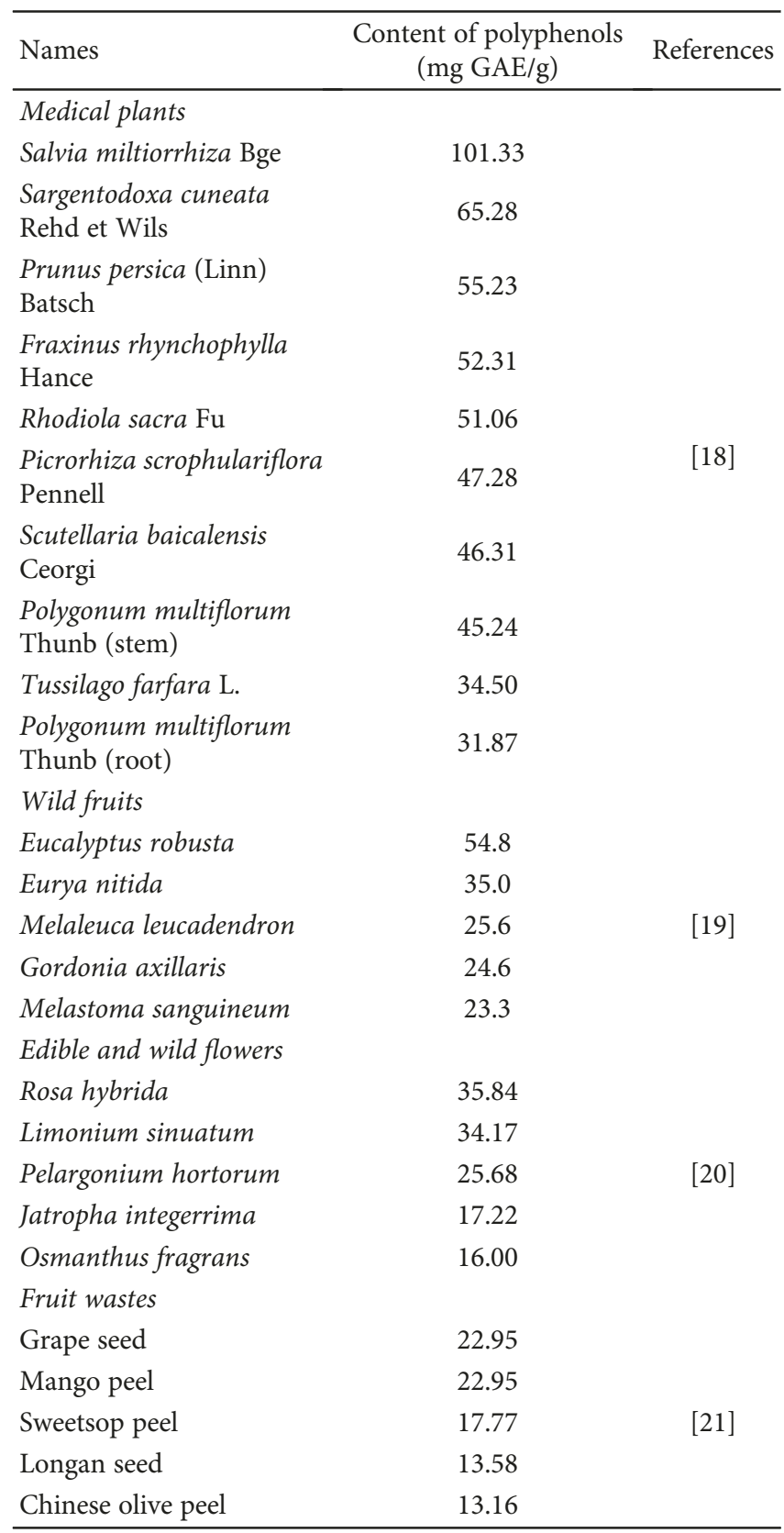

accepted therapies to treat this disease in human at present [1]. The direct consequences of ethanol metabolism are related to ROS production, mitochondrial injury, and hepatic steatosis, which are the common features of acute and chronic alcohol exposures [35]. Alcoholic fatty liver is a reversible condition, but it can potentiate the development of alcoholic hepatitis and cirrhosis by promoting free radical generation. A great deal of polyphenols has been found to be beneficial for alcoholic liver injury associating with hepatic lipid metabolism regulation and antioxidative stress. Total flavonoids from Litsea coreana showed therapeutic effects on alcoholic fatty liver via suppression of hepatic adipose differentiation-related protein (ADRP) [36]. The supplementation of a novel flavonoid, fisetin, in the diet at $10 \mathrm{mg} / \mathrm{kg} /$ day 
also showed remarkable beneficial effect on alcohol-induced liver injury. Hepatic NADPH oxidase 4 levels along with plasma hydrogen peroxide and hepatic superoxide and 4-hydroxynonenal levels increased by alcohol consumption were reduced by fisetin supplementation. Fisetin attenuated liver steatosis through enhancing plasma adiponectin levels and hepatic protein expressions of p-AMPK, acyl-CoA oxidase 1 (ACOX1), cytochrome P450 4A (CYP4A), and microsomal triglyceride transfer protein (MTTP) [37]. In a binge drinking mouse model, a polymethoxy flavonoid-rich Citrus aurantium extract alleviated alcohol-induced liver injury through activating lipid metabolism-related signals and regulating AMPK and Nrf2-related pathway signaling [38]. In mice model with chronic plus binge alcohol feeding, luteolin attenuated the liver injury via downregulation of lipogenic genes including sterol regulatory element-binding protein 1c (SREBP-1c), fatty acid synthase (FASN), acetylCoA carboxylase (ACC), and stearoyl-CoA desaturase (SCD1), suggesting its significant effect on alleviating liver steatosis [39]. In another study, oligomeric proanthocyanidins, a set of bioflavonoid complexes having strong free radical scavenging ability, protected liver from alcoholinduced injury and steatosis through decreasing the expressions of lipid synthesis genes and inflammation genes including SREBP-1c, SREBP2, interleukin 1 beta (IL-1 $\beta$ ), IL-6, and TNF- $\alpha$, indicating that AMPK activation might be involved in the underlying mechanism [40].

During the metabolic processes of alcohol in the liver via dehydrogenase system and microsomal ethanol oxidizing system (MEOS), NADH or $\mathrm{NADP}^{+}$are generated in bulk, with the consequence of increased ROS, eventually resulting in cellular and tissue injury [1]. With better understanding of the role of oxidative stress in the initiation and advancement of ALD, therapies targeting on enhancing antioxidant defense have been considered promising. In an in vitro study, it was found that Ecklonia cava polyphenol served as a promising candidate for inhibiting alcohol-induced hepatic damage via regulating alcohol metabolic enzymes including CYP2E1 and $\mathrm{ADH}$ in a cyclic AMP-dependent manner [41]. Two ellagitannins, geraniin and amariin, which belong to a type of polyphenol formed mainly from the oxidative linkage of galloyl groups in 1,2,3,4,6-pentagalloyl glucose, were isolated from Phyllanthus amarus. It was found that both of them could protect mouse liver from alcoholic cytotoxicity through restoring antioxidant enzymes, inhibiting oxidation of lipid and protein, ceasing formation of 8-hydroxy-2-deoxyguanosine, and modulating Bcl-2associated $\mathrm{X}(\mathrm{Bax}) / \mathrm{Bcl} 2$ ratio against apoptosis [42].

Regarding action mechanisms of polyphenols in ALD, in addition to regulating hepatic steatosis and antioxidative stress, several other mechanisms have also been proposed. For example, it was demonstrated that polyphenols could suppress the expression of genes related to cell stress and upregulate genes involved in bile acid synthesis, unsaturated fatty acid elongation, and tetrahydrofolate synthesis [43]. Liver iron overload has long been considered as pathogenic factors of ALD. Iron is involved in the Fenton pathway, and it accumulates during chronic hepatic inflammation and catalyzes hydroxyl radical-mediated oxidative injury [44]. The deposition of iron in the liver may increase the risk of death in patients with ALD [44]. Therefore, removal of iron represents an important therapeutic strategy for ALD treatment. In a study, epigallocatechin-3-gallate (EGCG) has been demonstrated to ameliorate alcoholic liver injuries associated with its iron-chelating property. It affected hepatic iron uptake and inhibited iron absorption in the small intestinal via upregulating hepcidin mRNA levels and transferrin as well as hepatic transferrin receptor protein levels, thus reducing serum and hepatic iron levels [45].

3.3. NAFLD. Nonalcoholic fatty liver disease (NAFLD), defined as genetic-environmental-metabolic stress-related disease with a spectrum of liver disorders, affects $10 \%$ to $24 \%$ of the population worldwide, and the prevalence has even been up to $75 \%$ in obese people [46]. Currently, no evidence-based pharmacological therapy is available for NAFLD. A multitude of pathways implicated in the etiology of NAFLD makes the treatment challenging. Ideally, the treatment should address all these pathways [47]. Free fatty acids, oxidative stress, and inflammation that cause insulin resistance, hepatocyte fat accumulation, and cellular injury are the major processes involved in the progression of NAFLD [47]. Reasonably, polyphenols with remarkable ability in metabolism regulation, antioxidant, and antiinflammation have been considered as promising therapies of NAFLD. The mechanisms underlying beneficial effects of many polyphenols on NAFLD have been extensively studied in recent years. In addition to regulation of classical intracellular signaling transduction, some of them were demonstrated to exert therapeutic effects via emerging mechanisms such as mediating microRNAs and gut microbiota regulation.

3.3.1. Intracellular Signaling Transduction. Signaling pathways are associated with insulin resistance, oxidative stress, and inflammation include NF- $\kappa \mathrm{B}$, AMPK, Janus kinase/signal transducers and activators of transcription (JAK/STAT), peroxisome proliferator-activated receptors (PPARs), SREBP-1c, phosphatidylinositol 3-kinase/protein kinase B (PI3K/Akt), and TLR [5]. Blocking the transmission of above pathways within the liver cells would be effective for the prevention and treatment of NAFLD. Polyphenols may prevent hepatocyte injury associated with NAFLD through several signaling pathways: (1) suppressing activation of NF$\kappa \mathrm{B}$ pathway to inhibit inflammation; (2) increasing $\beta$-fatty acid oxidation by upregulating $\operatorname{PPAR} \alpha$; (3) inhibiting lipogenesis via downregulation of SREBP-1c by activating AMPK; and (4) enhancing antioxidant defense through Nrf2 pathway, as shown in Figure 2.

NF- $\kappa$ B pathway regulates a variety of cytokines involved in inflammation. As a matter of fact, the anti-inflammatory effects of polyphenols have been generally subscribed to the inhibition of canonical $\mathrm{NF}-\kappa \mathrm{B}$ pathway. The canonical $\mathrm{NF}-\kappa \mathrm{B}$ pathway is activated by proinflammatory signals, causing the degradation of $\mathrm{I} \kappa \mathrm{B}$ kinase (IKK) complex to release $\mathrm{NF}-\kappa \mathrm{B}$ into the nucleus, with the consequence of inflammatory response [46]. It was reported that kaempferol inhibited the phosphorylation of insulin receptor substrate 1 


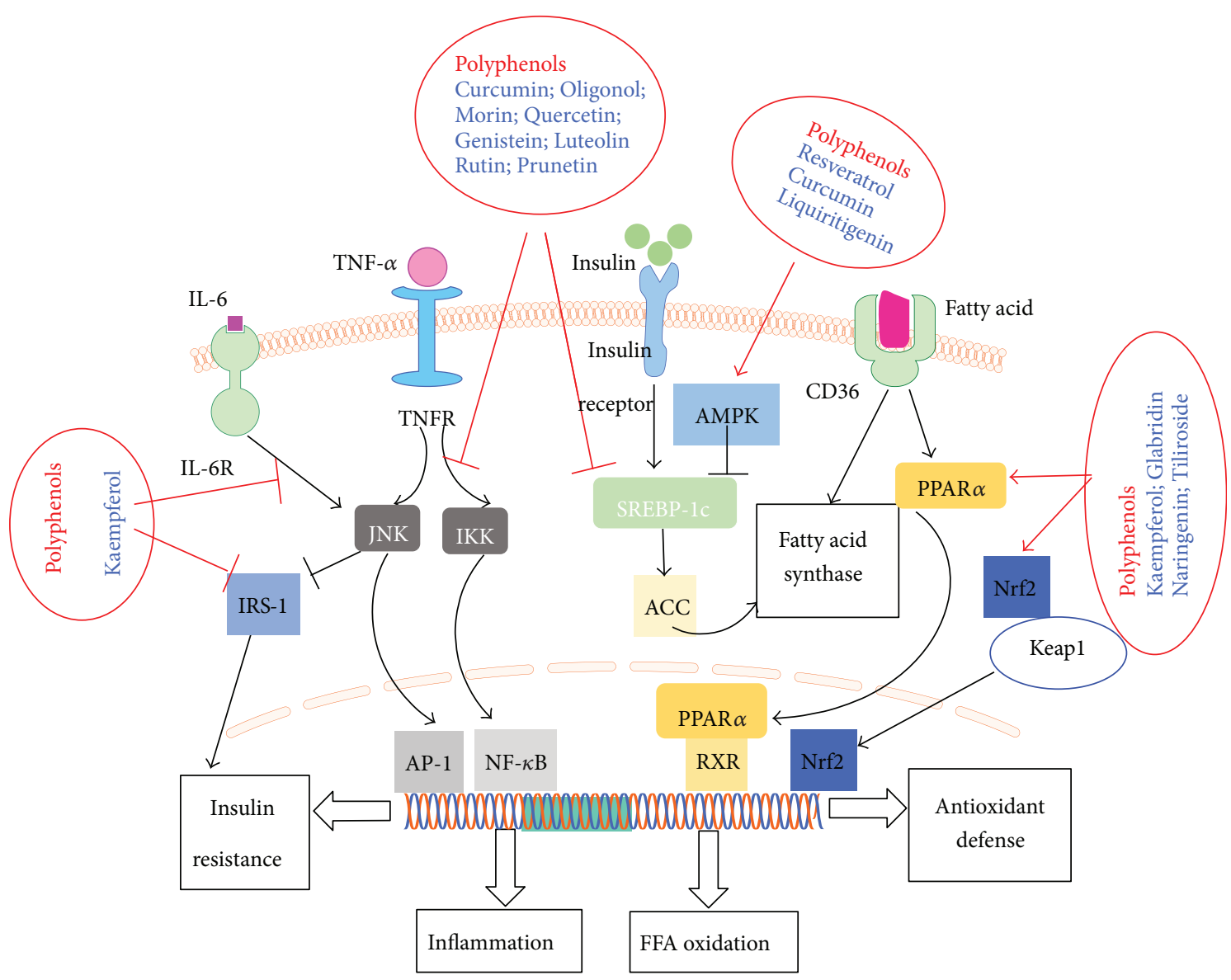

Figure 2: Intracellular signaling transduction mediated by polyphenols for the treatment of NAFLD. Polyphenols may prevent injury in hepatocytes associated with NAFLD through several signaling pathways: (1) suppressing activation of NF- $\kappa$ B pathway to inhibit inflammation; (2) increasing $\beta$-fatty acid oxidation by upregulating PPAR $\alpha$; (3) inhibiting lipogenesis via downregulation of SREBP-1c by AMPK activation; and (4) enhancing antioxidant defense through Nrf2 pathway.

(IRS-1), IKK $\alpha$, and IKK $\beta$, accompanied with reduction of $\mathrm{NF}-\kappa \mathrm{B}$ in nucleus and cytoplasm and further reduced TNF$\alpha$ and IL- 6 levels in mice with insulin resistance and type 2 diabetes mellitus [48]. Other polyphenols such as curcumin [49], morin [50], oligonol [51], and quercetin [52] also have been indicated to inhibit $N F-\kappa B$ pathway in NAFLD. MAPK, a class of serine/threonine protein kinase widely expressed in mammalian cells including extracellular signal-regulated kinases (ERKs), JNK, and p38MAPK, is also closely associated with inflammation. Regulating MAPK, in particular with JNK and p38MAPK, has been regarded as the potential action mechanism of some polyphenols for the treatment of NAFLD. For example, cocoa flavonoids and apple polyphenols showed beneficial effects on redox balance and insulin resistance by targeting MAPKs in the context of NAFLD $[53,54]$.

PPAR, a group of nuclear receptors that play a role in lipid and glucose metabolism, is one of the promising targets in terms of regulating metabolic process [46]. Among the three types of PPARs that have been identified, PPAR $\alpha$ and PPAR $\gamma$ have been highlighted for their involvement in the pathogenesis of NAFLD [47]. PPAR $\alpha$ is highly expressed in the liver to regulate free fatty acid (FFA) transport and stimulates enzymes participated in $\beta$-oxidation.
Furthermore, it attenuates inflammation by inhibition of $\mathrm{NF}-\kappa \mathrm{B}$ and C-reactive protein expression [46]. Therefore, stimulation of PPAR $\alpha$ is expected to relieve steatosis and hepatic inflammation. A great deal of study has demonstrated that many polyphenols can stimulate PPAR $\alpha$. Some of them act as ligands and agonists of $\operatorname{PPAR} \alpha[55,56]$, while others, such as kaempferol [57], naringenin [58], tiliroside [59], and glabridin [60], can upregulate $\operatorname{PPAR} \alpha$ gene and/or protein expression. Flavonoid-enriched extract from Hippophae rhamnoides seed decreases high-fat diet(HFD-) induced obesity, hypertriglyceridemia, and hepatic triglyceride accumulation via regulation of $\operatorname{PPAR} \alpha$ and PPAR $\gamma$ gene expression and suppression of adipose tissue inflammation [61]. Compared with other drugs, such as glitazones, polyphenols have an advantage of partial activation of PPARs. This significantly reduces the risk of serious side effects by the use of full agonists, suggesting the great potency of polyphenols for the prevention and treatment of NAFLD. Another identified target in terms of metabolic regulation for the treatment of NAFLD is SREBP-1c, a transcription factor that regulates de novo lipogenesis through mediation of lipogenic enzymes and genes [46]. The increased expression of hepatic SREBP1c promotes the progression of steatosis. A variety of 
polyphenols, such as genistein [62], luteolin [63], rutin [64], and prunetin [65], have been demonstrated to inhibit SREBP-1c, mainly via directly downregulation of SREBP$1 c$ protein and gene expression, activation of AMPK, or inhibition of liver $\mathrm{X}$ receptor $\alpha(\mathrm{LXR} \alpha)$ that controls SREBP-1c transcription. In addition, as hyperinsulinemia stimulates SREBP-1c transcription, polyphenols might also decrease SREBP-1c by improving insulin sensitivity and controlling insulin levels. Furthermore, it has been proposed that polyphenols could inhibit SREBP-1c through inhibition of ER stress [66].

AMPK, a heterologous trimeric protein kinase that is formed by $\alpha, \beta$, and $\gamma$ subunits, is a vital regulator of cellular energy homeostasis [46]. It controls fatty acid metabolism through mediating the fatty acid biosynthetic pathway. In the pathogenesis of NAFLD, AMPK is closely related with insulin resistance and hepatic lipid accumulation [47]. AMPK activation inhibits the expression of ACC and FAS by downregulating SREBP-1c, thus reducing synthesis of fatty acids, cholesterol, and triglycerides and promoting fatty acid uptake and $\beta$-oxidation [46]. There is a great deal of polyphenols that serves as AMPK activators to protect hepatocytes against damage, such as resveratrol [67] and curcumin [49]. Hawthorn leaf flavonoids alleviated NAFLD by enhancing the adiponectin/AMPK pathway to regulate SREBP-1c, PPAR $\alpha$, and related downstream targets [68]. Liquiritigenin protected hepatocytes against oxidative hepatic injury and mitochondrial dysfunction via AMPK activation by liver kinase B1 (LKB1) pathway as well as Farnesoid X receptor (FXR) induction [69].

\subsubsection{Other Emerging Mechanisms. MicroRNAs (miRNAs)} are small noncoding RNAs that regulate gene expression at the posttranscriptional level. The role of miRNAs in NAFLD has been revealed and emphasized in recent years. A study measured circulating miRNAs in 84 nonalcoholic steatohepatitis (NASH) patients found that miR-122, miR-192, miR-19a, miR-19b, miR-125b, and miR-375 were significantly upregulated. Furthermore, the expression of miR122, miR-192, and miR-375 correlated with disease severity. Increasing evidences claim that these circulating miRNAs not only serve as biomarkers for diagnosis but also play important roles in the intercellular communication and disease progression, which makes them attractive therapeutic targets. Exogenous factors such as polyphenols are suspected to affect miRNA concentrations to treat NAFLD. For example, miR-33 and miR-122, serving as major regulators of lipid metabolism in liver, were decreased in HFDinduced obese rats. It has been demonstrated that reduction of miR-122 induces IR, which can be reversed by licorice flavonoid [70]. Long-term supplementation with a low dose of proanthocyanidins could normalize liver miR-33a and miR-122 levels [71]. Plant-derived polyphenols were demonstrated to mediate the expression of miRNA paralogs miR-103/107 and miR-122 to attenuate NAFLD in hyperlipidemic mice [72]. Lychee pulp phenolics, mainly including quercetin 3-O-rutinoside-7-O-alpha-L-rhamnosidase (quercetin 3-rut-7-rha), rutin, and (-)-epicatechin, ameliorated liver lipid accumulation by reducing miR-33, which directly modulated adenosine triphosphate- (ATP-) binding cassette transporters $\mathrm{ABCA} 1$ and carnitine palmitoyltransferase 1 (CPT1) as well as miR-122 expression and indirectly regulated FAS, in mice with HFD [73].

Gut microbiota has been intensively researched due to its vital role in maintaining human health [74]. It is believed to be involved in obesity, metabolic syndrome, and the development of NAFLD [74]. A study has indicated that quercetin possessed ability of modulating intestinal microbiota imbalance and related gut-liver axis activation. Dysbiosis induced by HFD was accompanied by endotoxemia, intestinal barrier dysfunction, and gut-liver axis alteration, which could regulate TLR-4-NF- $\kappa$ B signaling pathway activation, resulting in inflammasome initiation response and reticulum stress pathway induction [52]. Quercetin could revert gut microbiota imbalance and TLR-4 pathway induction, resulting in the blockage of deregulation of lipid metabolism genes. The striking benefits of polyphenols on NAFLD in mediating gut microbiota should be explored more in future studies, which might offer a new direction in understanding their action mechanisms.

The immune system is extensively implicated in the pathogenesis of NAFLD. Autophagy was recently identified as a critical protective mechanism during NAFLD development [75]. Lipophagy, defective autophagy of lipid droplets in hepatocytes, has recently been identified as a possible pathophysiological mechanism of NAFLD. Bergamot polyphenol fraction treatment $(50 \mathrm{mg} / \mathrm{kg} /$ day supplemented with drinking water for 3 months) potently counteracted the increase of serum triglycerides, which was accompanied with increased levels of LC3 and Beclin 1 and reduced SQSTM1/ p62, suggesting autophagy stimulation [76]. The development of a preventive treatment targeting circulating monocytes and hepatic macrophages as well as other immune cells such as $\mathrm{CD} 4^{+}$cells has been getting increased attention. Curcumin, possessing remarkable ability to prevent HFDinduced hepatic injury and metabolic derangements, was found to regulate intrahepatic $\mathrm{CD} 4^{+}$cell accumulation and inhibit inflammatory and oxidative damage caused by linoleic acid and leptin on mouse liver macrophages [77]. Activated macrophages/Kupffer cells promote the progression of hepatic fibrogenesis and aggravate metabolic disorders such as insulin resistance. Dietary quercetin supplementation to obesity mice decreased levels of TNF- $\alpha$ and IL-6, while it increased the level of anti-inflammatory cytokine IL-10 in the livers, accompanied by macrophage phenotype switching, as evidenced by upregulated anti-inflammatory M2 macrophage marker genes arginase 1 and Mannose receptor C (Mrc1), and downregulated proinflammatory $\mathrm{M} 1$ macrophage marker genes TNF- $\alpha$ and nitric oxide synthase 2 (NOS2). The beneficial effect of quercetin on NAFLD might be associated with promoting hepatic macrophage polarization in favor of the M2 phenotype via Nrf2-mediated heme oxygenase-1 (HO-1) induction [78].

Furthermore, accumulating evidence revealed the critical role of endoplasmic reticulum (ER) in NAFLD [47]. ER is the site of triglyceride synthesis and nascent lipid droplet formation with function in synthesizing, folding, and transporting proteins [47]. The accumulation of misfolding proteins in 
the ER lumen causes unfolded protein response (UPR) via the activation of the ER stress sensor proteins including PERK, inositol-requiring enzyme 1 (IRE1), and activating transcription factor 6 (ATF6). Sustained unfolded protein response (UPR) induces ER stress and metabolic disruptions, facilitating inflammation and insulin resistance in adipocytes. Lipolysis in response to ER stress is triggered via cAMP/protein kinase A (PKA) and ERK1/2 signaling. Curcumin treatment inhibited adipose tissue ER stress by dephosphorylation of inositol-requiring enzyme $1 \alpha$ and eukaryotic initiation factor $2 \alpha$ and reduced cAMP accumulation by preserving phosphodiesterase $3 \mathrm{~B}$ induction, with the consequence of blockage of PKA/hormone-sensitive lipase lipolysis signaling, and thereby decreased glycerol and FFA release from adipose tissue [79]. Glycycoumarin, a representative of coumarin compounds isolated from licorice, showed inhibition of hepatocyte lipoapoptosis via suppressing ER stress-mediated JNK activation [80]. Furthermore, researches have reported that polyphenol extraction of grape [81] and its major bioactive compound resveratrol showed benefit for NAFLD partly through attenuating ER stress.

In addition, compelling evidence in recent years has demonstrated a significant link between NAFLD and cardiovascular disease (CVD) including coronary heart disease and stroke [82]. The likely of mechanisms underlying this association has been proposed involving genetic predisposition, insulin resistance, oxidative stress, chronic inflammation, atherogenic dyslipidemia, decreased adiponectin, and altered generation of pro- and anticoagulant factors [83]. In particular, among mechanisms linking CVD risk with hepatic steatosis, the most prominent factors are considered to be insulin resistance, chronic inflammation, oxidative stress, and atherogenic dyslipidemia [84]. The oxidative stress in NAFLD may induce alterations in endothelial function resulting in formation and deposition of oxidized lowdensity lipoprotein (LDL) in the subintimal space [82]. Therefore, therapeutic strategies targeting oxidative stress reduction in NAFLD patients for lowering CVD risk have been proposed. As an important category of antioxidants, polyphenols, such as resveratrol and silybin, have been attempted to reduce CVD risk in the setting of NAFLD [82]. Resveratrol, due to its potent effects on oxidative stress and inflammation, has become one of the most interesting candidates [84]. The effect of resveratrol on CVD protection has been demonstrated as evidenced by an improvement of CVD risk markers, such as endothelial function, echocardiographic parameters, and cytokine expression [85]. Studies, particularly long-term randomized clinical trials, evaluating the anticardiovascular effects of antioxidant treatment in patients with NAFLD are needed.

3.4. Viral Hepatitis. There are five well-characterized hepatotropic viruses, termed hepatitis A to hepatitis E. Among them, hepatitis B virus (HBV) and hepatitis C virus (HCV) are the most common types. In particular, HBV is a major cause of liver cirrhosis and HCC [86]. Though there is opportunity to prevent and treat viral hepatitis, all the currently approved antiviral drugs have their limitations [86]. For example, interferon has limited efficacy with a high incidence of adverse effects in some patients. As an alternative approach, natural products have provided great promises as potentially effective antiviral drugs. A broad spectrum of phytochemicals including flavonoids such as wogonin and polyphenolics such as geraniin has been isolated and investigated for antihepatitis virus activities in vitro as well as in vivo $[87,88]$. The underlying action mechanisms have been proposed mainly as prevention of virus entry, inhibition of viral antigen secretion, and suppression of DNA replication [89].

Several flavonoids have been identified as inhibitor of $\mathrm{HCV}$ and HBV entry. A potent inhibitor of hepatitis virus is EGCG, a well-known polyphenol in green tea. EGCG inhibited entry of HBV into hepatocytes via induction of clathrin-dependent endocytosis of sodium taurocholate cotransporting polypeptide from the plasma membrane followed by protein degradation and inhibited the clathrinmediated endocytosis of transferrin, without effect on HBV genome replication or virion secretion [90]. It can also potently inhibit HCV entry into hepatoma cell lines and primary human hepatocytes [91, 92]. Delphinidin, a plant pigment in flavonoid family that is responsible for the blue-purple color of flowers and berries, induced a bulging of the viral envelope to inhibit HCV attachment to the cell surface [93]. Tannic acid could inhibit HCV entry into Huh7.5 cells [94].

Plenty of studies have reported polyphenols with remarkable antihepatitis virus through inhibiting virus replication via different mechanisms. Silibinin served as direct inhibitor of HCV RNA-dependent RNA polymerase [95]. Epicatechins, one of the phenolic in green tea, can inhibit HCV replication via cycloxygenase- 2 and relieve inflammation induced by virus [96]. The flavonoid apigenin inhibited HCV replication by decreasing mature miRNA122 levels, which was a liver-specific miRNA for positive regulation of HCV replication [97]. Curcumin suppressed HBV via downregulation of the metabolic coactivator PGC- $1 \alpha$, a starvation-induced protein that has been shown to robustly coactivate HBV transcription [98]. The flavonoid prescription baicalin-linarin-icariin-notoginsenoside R1 had curative effect on duck virus hepatitis caused by duck hepatitis A virus type 1 (DHAV-1), which could inhibit DHAV-1 reproduction by destroying its adsorption and release [99]. Quercetin significantly reduced the viral genome replication, the production of infectious HCV particles, and the specific infectivity of the newly produced viral particles [100]. Nonstructural protein 3 (NS3) encoded by HCV genome has been regarded as a potential anti-HCV drug target as it is vital for viral replication. Several anthracyclines with hydroxyanthraquinone moiety structure were found to inhibit NS3 helicase. And mitoxantrone, a hydroxyanthraquinone analogue, was also known to be inhibitor of NS3 helicase [101]. Additionally, quercetin suppressed HCV via inhibition of NS3 protease activity [102]. Another target for HCV, nonstructural protein 5B (NS5B), could be inhibited by EGCG [103]. Other compounds showing antiviral activities including kaempferol 8-methyl ether, quercetin 3-methyl ether, kaempferol [104], chlorogenic acid analogues, isoliquiritigenin, glycycoumarin, [105], glycyrin, glycyrol, liquiritigenin, 
isoliquiritigenin, licochalcone $\mathrm{A}$, and glabridin chlorogenic acid analogues [106] identified from natural products such as tea and medicinal plants would also be good candidates for development of antivirals against hepatitis virus.

3.5. Liver Fibrosis and Cirrhosis. Liver fibrosis is a woundhealing response to hepatic injury. It is characterized by the accumulation of extracellular matrix (ECM), which leads to a progressive substitution of liver parenchyma by scar tissue [3]. Sustained fibrogenesis would result in cirrhosis, the consequence of progressive fibrosis with a poor outcome and high mortality, characterized by a distortion of the liver parenchyma and vascular architecture. Due to the vital role of ECM in fibrogenesis, matrix-expressing cells have been considered as the vital cellular basis of liver fibrogenesis [3]. Among them, hepatic stellate cells (HSCs), the major cell type responsible for ECM deposition, have been extensively studied. Upon chronic liver injury, quiescent HSCs undergo morphological and phenotypical transdifferentiation into contractile and highly proliferative myofibroblasts with collagen-producing ability. Plenty of polyphenols were found to protect liver from fibrosis via suppression of the activation of HSCs such as apigenin, EGCG, quercetin, icaritin, curcumin, and resveratrol [107-113]. The mechanisms underlying the inhibition of activated HSCs have been ascribed to upregulation of C1QTNF2, MMPs, or miR-221 to accelerate osteopontin degradation and downregulation of PPAR $\gamma$ or membrane translocation and gene expression of GLUT2. Polyphenols such as hyperoside, morin, gallic acid, and quercetin have been revealed that they exert antifibrosis effect via promoting apoptosis of activated HSCs, primarily associated with NF- $\kappa \mathrm{B}$ and TNF- $\alpha$ signaling $[114,115]$. Furthermore, there is mounting evidence indicated that many flavonoids could decrease proliferation of HSCs and inhibit expression of profibrogenesis-related genes in HSCs. For example, chrysin and tricin inhibited proliferation of HSCs via suppressing TGF- $\beta 1 /$ Smad pathway and blocking tyrosine phosphorylation of platelet-derived growth factor (PDGF) receptor, respectively $[116,117]$. Chlorogenic acid suppressed profibrotic action of HSCs via inhibition of NOX/ROS/MAPK pathway, while resveratrol can suppress the activation of $\mathrm{NF}-\kappa \mathrm{B}$ and Akt, reducing expression of related profibrogenesis genes in activated HSCs [118, 119]. EGCG and wogonoside regulate profibrogenic/antifibrogenic balance via inhibition of PI3K/Akt/Smad pathway and PI3K/Akt/ mTOR/ribosomal protein S6 kinase $70 \mathrm{kDa}$ (p70S6K), respectively [120, 121]. We summarized the major action mechanisms of a variety of polyphenols on HSCs in Figure 3. In addition to action on HSCs, several polyphenols such as morin, chlorogenic acid, and curcumin also showed antifibrotic capacities through attenuating oxidative stress and inflammation response via different mechanisms including inhibition of TLR4/MyD88/NF- $\kappa \mathrm{B}$ signaling pathway, suppressing the advanced glycation end- (AGE-) mediated induction of receptor for advanced glycation end (RAGE) gene expression by increasing PPAR $\gamma$ and stimulating glutathione (GSH), and regulating PPAR signal pathway and the interaction with FXR [122-124]. In summary, the potential mechanisms of some polyphenols with remarkable antifibrotic ability in vivo and in vitro have been listed in Table 2. The promising antifibrotic efficiencies of these compounds from food and plants with well-recognized action mechanisms make them deserve further exploration in a clinical study in the future.

3.6. Liver Cancer. Liver cancer, the sixth most common cancer with high mortality worldwide, represents a major international health problem. Increasing epidemiological evidence indicated that a diet rich in fruits and vegetables could lower the risk of certain cancers, including liver cancer, which has been partly attributed to natural polyphenols contained [128]. A variety of natural polyphenols have been studied for the prevention and treatment of liver cancer [129]. Potential mechanisms have been proposed as proapoptosis and antiproliferation effect to liver cancer cells, antiangiogenesis, inhibition of invasion, and metastasis, as well as other modulation of multiple molecular events involved in carcinogenesis.

A plenty of polyphenols showed remarkable properties of promoting apoptosis and suppressing proliferation of liver cancer cells via various pathways [130-133]. Many flavones, a class of flavonoids based on the backbone of 2-phenylchromen-4-one, such as vitexin, luteolin, chrysin, isoorientin, oroxylin A, wogonin, and baicalein, have been found to induce apoptosis and inhibit proliferation of a variety of HCC cell lines by different or overlapped mechanisms. UPR pathway, mTOR pathway, ROS pathway, JNK pathways, caspase-dependent, and caspase-independent apoptotic signaling pathways have been extensively proposed for anticancer ability of these flavones. Flavanones including eriodictyol and hesperidin induce HepG2 cell apoptosis mainly via regulation of apoptotic proteins such as Bax and Bcl-2, mitochondrial pathway, and death receptor pathway. Other flavonoids including flavanols, flavanonol, flavonol, and isoflavones, which have been demonstrated to induce apoptosis of liver cancer cells in vivo and in vitro, are summarized in Table 3. Nonflavonoids, such as gigantol, chlorogenic acid, and gallic acid, mediate the apoptosis of HCC cells principally through induction of ER stress and regulating mitochondrial-mediated pathways. As a matter of fact, most polyphenols induce apoptosis and inhibit proliferation of HCC cells via multiple targets and pathways. For example, baicalein caused HepG2 cell apoptosis via inhibiting the $\mathrm{PKB} / \mathrm{mTOR}$ pathway or blocking MEK-ERK signaling [134, 135] while another flavone compound oroxylin A suppressed PI3K-PTEN-Akt-mTOR signaling pathway and activated the PERK-eIF2 $\alpha$-ATF4-CHOP branch of the UPR pathway [136, 137] to mediate apoptosis. EGCG, a famous flavanol in tea, showed remarkable ability to induce apoptosis of a variety of liver cancer cells such as SMMC7721, SK-hep1, HLE, HepG2, HuH-7, and PLC/PPF/5 cells [132]. Its underlying mechanisms have been revealed as inhibition of receptor tyrosine kinase, downregulation of PI3K/AKT activity, downregulation of $\mathrm{Bcl}-2 \alpha$, and $\mathrm{Bcl}-\mathrm{xl}$ by inactivation of NF$\kappa \mathrm{B}$ [138-140]. Additionally, fisetin, a common flavonoid found in many fruits and vegetables, suppressed proliferation of liver cancer cells via modulation of multiple signaling pathways including CDK5 signaling, Nrf2-mediated 


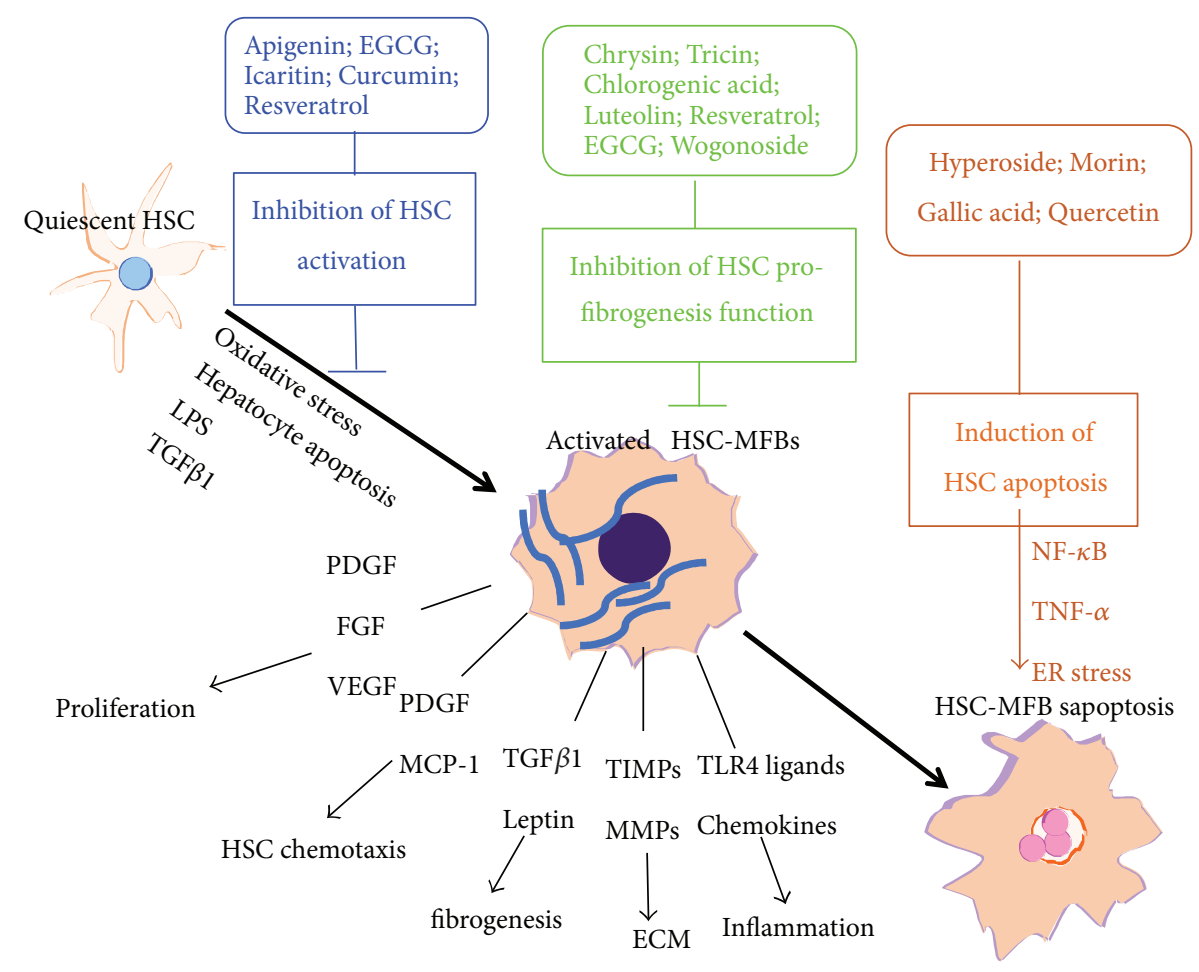

FIgURE 3: The major action mechanisms of a variety of polyphenols on HSCs. Apigenin, EGCG, icaritin, curcumin, and resveratrol could inhibit the activation of HSCs; chrysin, tricin, chlorogenic acid, luteolin, resveratrol, EGCG, and wogonoside suppress the profibrogenesis function of HSCs; hyperoside, morin, gallic acid, and quercetin can induce HSC apoptosis. PDGF: platelet-derived growth factor; FGF: fibroblast growth factor; MCP-1: monocyte chemoattractant protein-1; TIMP1: TIMP metallopeptidase inhibitor 1.

oxidative stress response, glucocorticoid signaling, and ERK/ MAPK signaling [141]. The character of modulation of multiple targets and pathways makes them more promising in application of developing anticancer drugs or dietary supplements for HCC patients.

Furthermore, several flavonoids have been demonstrated to exert beneficial effects against liver cancer via antiangiogenesis. Flavones including eupafolin and morusin showed significant antiangiogenic abilities by in vitro and in vivo studies. Eupafolin could block vascular endothelial growth factor- (VEGF-) induced activation of vascular endothelial growth factor receptor 2 (VEGFR2) in Akt activity in human umbilical vascular endothelial cells and inhibit Akt activity and VEGF secretion in HepG2 [142]. The other flavone, morusin, inhibited angiogenesis in HepG2 xenograft mice model via attenuation of the IL- 6 and signal transducer and activator of transcription 3 (STAT3) signaling pathway [143]. Morin, a type of flavonol belonging to flavonoid, inhibits tumor growth and angiogenesis in rats with diethylnitrosamine- (DEN-) induced HCC through upregulation of NF- $\kappa$ B-p65 and COX-2 and reducing MMPs [144]. Resveratrol also showed effects on suppressing angiogenesis in mice with HCC xenograft. The mechanism underlying its antiangiogenesis is through inhibiting VEGF expression by a NF- $\kappa$ B-mediated pathway [145].

In addition to antiangiogenesis, increasing studies indicated that a variety of polyphenols could inhibit invasion and metastasis in liver cancer. Flavanones including hesperidin and naringenin, flavones including luteoloside and wogonin, and other flavonoids such as galangin, EGCG, and genistein have been reported by various studies for reducing invasion and metastasis of liver cancer cells in vivo and in vitro. It is interesting to note that hesperidin and naringenin, two types of flavanone, inhibited invasion and metastasis of liver cancer cells such as HepG2 via similar mechanisms, reducing MMP-9 expression through the inhibition of NF- $\kappa \mathrm{B}$ and activator protein 1 (AP-1) activity, suggesting potential structure-activity relationship might exist between flavanone and NF- $\kappa \mathrm{B} / \mathrm{AP}-1$ pathways. Additionally, phenolic compounds, theaflavins and (-)-oleocanthal suppressed the growth and metastasis through the blockage of STAT3 pathway. Their structure-activity relationship deserves to be further explored in the future. Other flavonoids possessing anti-invasion or antimetastasis effects by various pathways in HCC have also been summarized in Table 3.

Recently, several polyphenols have been demonstrated to reduce carcinogenesis. Curcumin treatment effectively reduced the progression of NASH to HCC by suppressing the protein expression of glypican-3, VEGF, and prothrombin in the NASH liver [86]. The upregulation of self-renewal Wnt/ $\beta$-catenin, Hh/Gli1 pathways, and their associated genes cyclin D1, cMyc, and epidermal growth factor receptor (EGFR) along with downregulation of Ecadherin during the carcinogenesis processes was found to be modulated by EGCG/theaflavins [146, 147]. In addition, some emerging pathways have been proposed to be involved in mechanisms of polyphenols' anticancer effect. 
TABLE 2: The potential antifibrotic mechanisms of some polyphenols.

\begin{tabular}{|c|c|c|c|c|}
\hline Effects & Polyphenol & Model & Mechanisms & Ref. \\
\hline \multirow{6}{*}{$\begin{array}{l}\text { Inhibition of HSC } \\
\text { activation }\end{array}$} & Apigenin & In vitro HSCs & Upregulating C1QTNF2 expression & {$[107]$} \\
\hline & EGCG & $\begin{array}{l}\text { In vitro HSCs \& thioacetamide- } \\
\text { treated animal }\end{array}$ & $\begin{array}{l}\text { Upregulating miR-221 to accelerate } \\
\text { osteopontin degradation }\end{array}$ & {$[108]$} \\
\hline & Quercetin & Rats with CCl4-induced fibrosis & $\begin{array}{l}\text { Activation of MMPs and regulating } \\
\text { profibrogenic/antifibrogenic molecules balance }\end{array}$ & [109] \\
\hline & Icaritin & $\begin{array}{l}\text { In vitro HSC-T6 and LX-2 HSC } \\
\text { lines \& rats with CCl4 } \\
\text { or CBDL-induced fibrosis }\end{array}$ & $\begin{array}{l}\text { Dependent on mitochondrial-activated } \\
\text { apoptosis }\end{array}$ & {$[110]$} \\
\hline & Curcumin & In vitro HSCs \& animal model & $\begin{array}{l}\text { Suppressing membrane translocation } \\
\text { and gene expression of GLUT2; inhibiting } \\
\text { PPAR } \gamma \text { via regulation of DLK1 protein partly } \\
\text { mediated by interruption of Shh signaling pathway }\end{array}$ & {$[111,112]$} \\
\hline & Resveratrol & $\begin{array}{l}\text { Rats with } \\
\mathrm{N}^{\prime} \text {-nitrosodimethylamine- } \\
\text { induced liver fibrosis }\end{array}$ & Relieving oxidative damage & {$[113]$} \\
\hline \multirow{4}{*}{ Induce HSC apoptosis } & Hyperoside & In vitro human LX-2 HSCs & $\begin{array}{l}\text { Inhibiting the DNA-binding activity of } \\
\text { NF- } \kappa \text { B and altered genes related to apoptosis }\end{array}$ & {$[125]$} \\
\hline & Morin & In vitro HSCs & Suppressing canonical NF- $\kappa \mathrm{B}$ signaling & \\
\hline & Gallic acid & In vitro HSCs & Regulating TNF- $\alpha$ signaling pathway & {$[114]$} \\
\hline & Quercetin & In vitro HSCs & Dependent on activation of ER stress & {$[115]$} \\
\hline \multirow{7}{*}{$\begin{array}{l}\text { Inhibit proliferation and } \\
\text { profibrogenesis-related } \\
\text { genes in HSCs }\end{array}$} & Chrysin & Mice with CCl4-induced fibrosis & Suppressing TGF- $\beta 1 /$ Smad pathway & {$[116]$} \\
\hline & Tricin & In vitro human HSC line LI90 & $\begin{array}{c}\text { Blocking tyrosine phosphorylation of PDGF } \\
\text { receptor }\end{array}$ & {$[117]$} \\
\hline & $\begin{array}{l}\text { Chlorogenic } \\
\text { acid }\end{array}$ & $\begin{array}{l}\text { In vitro HSCs \& CCl4-treated } \\
\text { rats }\end{array}$ & $\begin{array}{l}\text { Improving antioxidant capacity via activation of } \\
\text { Nrf2 pathway and suppressing profibrotic action via } \\
\text { inhibition of NOX/ROS/MAPK pathway }\end{array}$ & {$[118]$} \\
\hline & Luteolin & $\begin{array}{l}\text { In vitro rat HSCs and HSC-T6 } \\
\text { cells \& rat models induced by } \\
\text { CCl4, DMN, and BDL }\end{array}$ & $\begin{array}{l}\text { Increasing caspase } 3 \text { activity and p53 expression; } \\
\text { inducing G1 arrest with the decreased expression of } \\
\text { bcl-2, cyclin E, and p-Cdk-2; suppressing PDGF and } \\
\text { TGF1-simulated phosphorylation of AKT and } \\
\text { Smad pathway }\end{array}$ & {$[126]$} \\
\hline & Resveratrol & $\begin{array}{l}\text { In vitro human LX-2 HSCs \& } \\
\text { mice with CCl4-induced fibrosis }\end{array}$ & Suppressing the activation of NF- $\kappa \mathrm{B}$ and Akt & [119] \\
\hline & EGCG & In vitro HSC LX-2 \& BDL rats & Inhibiting PI3K/Akt/Smad pathway & {$[120]$} \\
\hline & Wogonoside & $\begin{array}{l}\text { In vitro HSC T6 cells \& mice } \\
\text { with CCl4-induced fibrosis }\end{array}$ & Inhibiting PI3K/Akt/mTOR/p70S6K & {$[121]$} \\
\hline \multirow{4}{*}{$\begin{array}{l}\text { Attenuate liver } \\
\text { injury and antifibrosis }\end{array}$} & Morin & Rats with CCl4-induced fibrosis & $\begin{array}{l}\text { Reducing oxidative stress, inflammatory } \\
\text { responses, and fibrogenic markers }\end{array}$ & {$[122]$} \\
\hline & $\begin{array}{l}\text { Chlorogenic } \\
\text { acid }\end{array}$ & Rats with CCl4-induced fibrosis & $\begin{array}{l}\text { Inhibition of TLR4/MyD88/NF- } \kappa \mathrm{B} \\
\text { signaling pathway }\end{array}$ & {$[123]$} \\
\hline & Curcumin & $\begin{array}{l}\text { Mice with type } 2 \text { diabetes } \\
\text { mellitus }\end{array}$ & $\begin{array}{l}\text { Suppressing the AGEs-mediated induction } \\
\text { of RAGE gene expression by increasing } \\
\text { PPAR } \gamma \text { and stimulating GSH }\end{array}$ & {$[124]$} \\
\hline & $\begin{array}{l}\text { Total } \\
\text { flavonoids } \\
\text { of Astmgali } \\
\text { Radix }\end{array}$ & Rats with fibrosis & $\begin{array}{l}\text { Regulating PPAR signal pathway } \\
\text { and the interaction with FXR }\end{array}$ & {$[127]$} \\
\hline
\end{tabular}

Glycycoumarin exerts antiliver cancer activity by directly targeting oncogenic kinase T-LAK cell-originated protein kinase (TOPK) [148]. Isoorientin possessed a notable hepatoprotective effect in the context of liver cancer, which might be mediated through the respiratory chain complexes and phase II detoxifying enzyme activities
[149]. Flavonoids activated pregnane X receptor-mediated CYP3A4 gene expression by inhibiting cyclin-dependent kinases in HepG2 liver carcinoma cells [150]. Furthermore, chlorogenic acid and catechins have been demonstrated to augment the antitumor effect of chemotherapeutic drugs for liver cancer. Chlorogenic acid could 


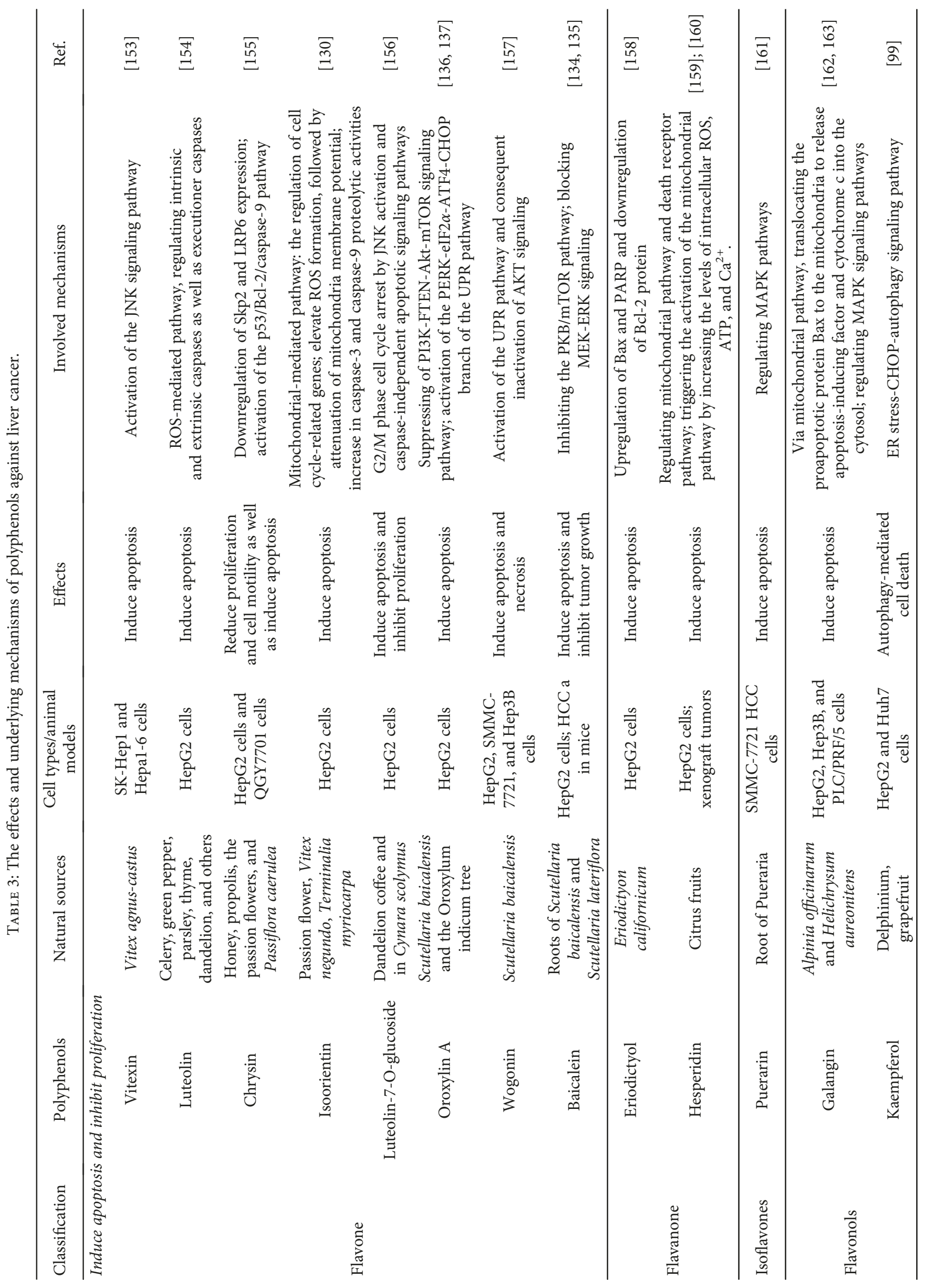




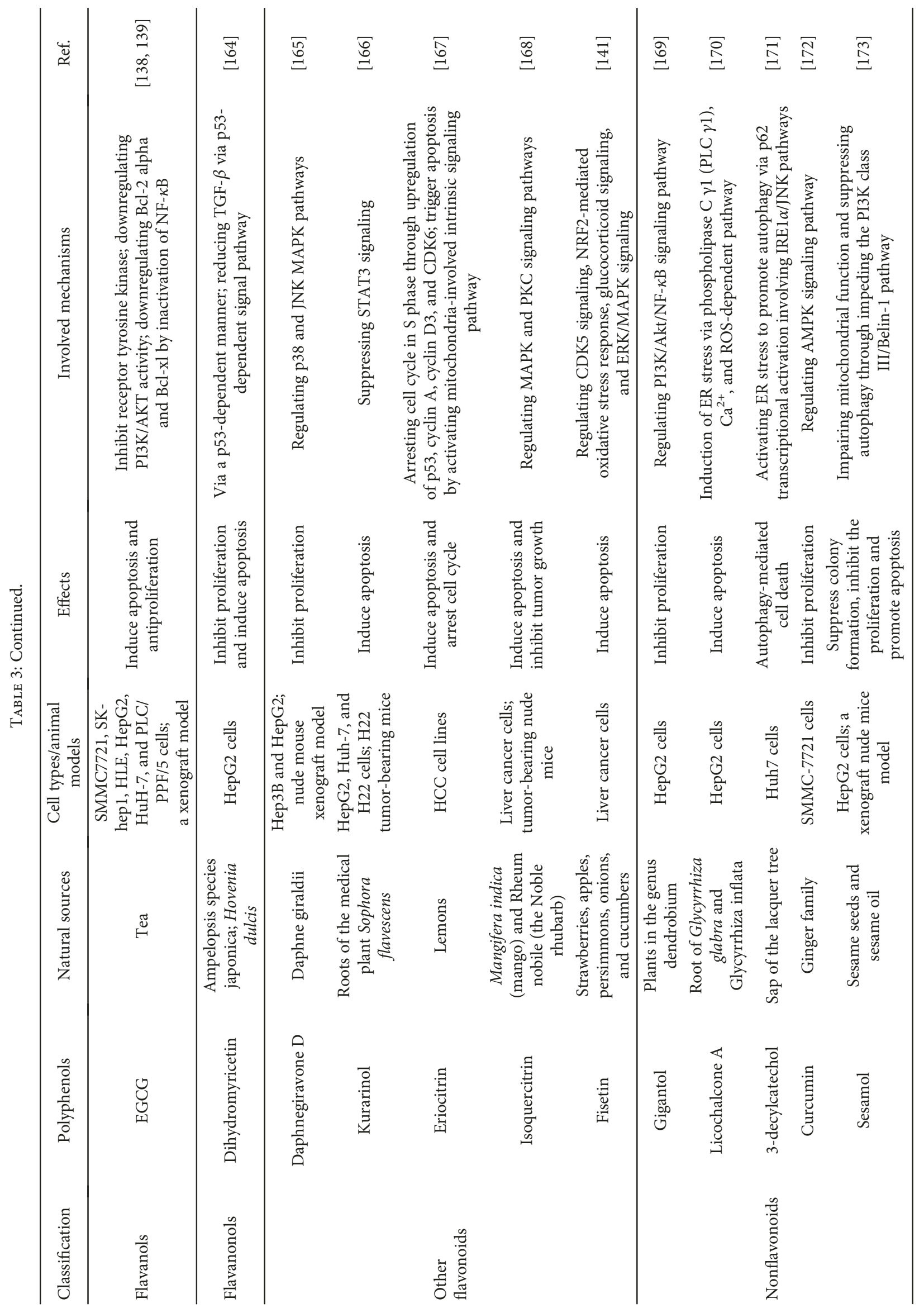




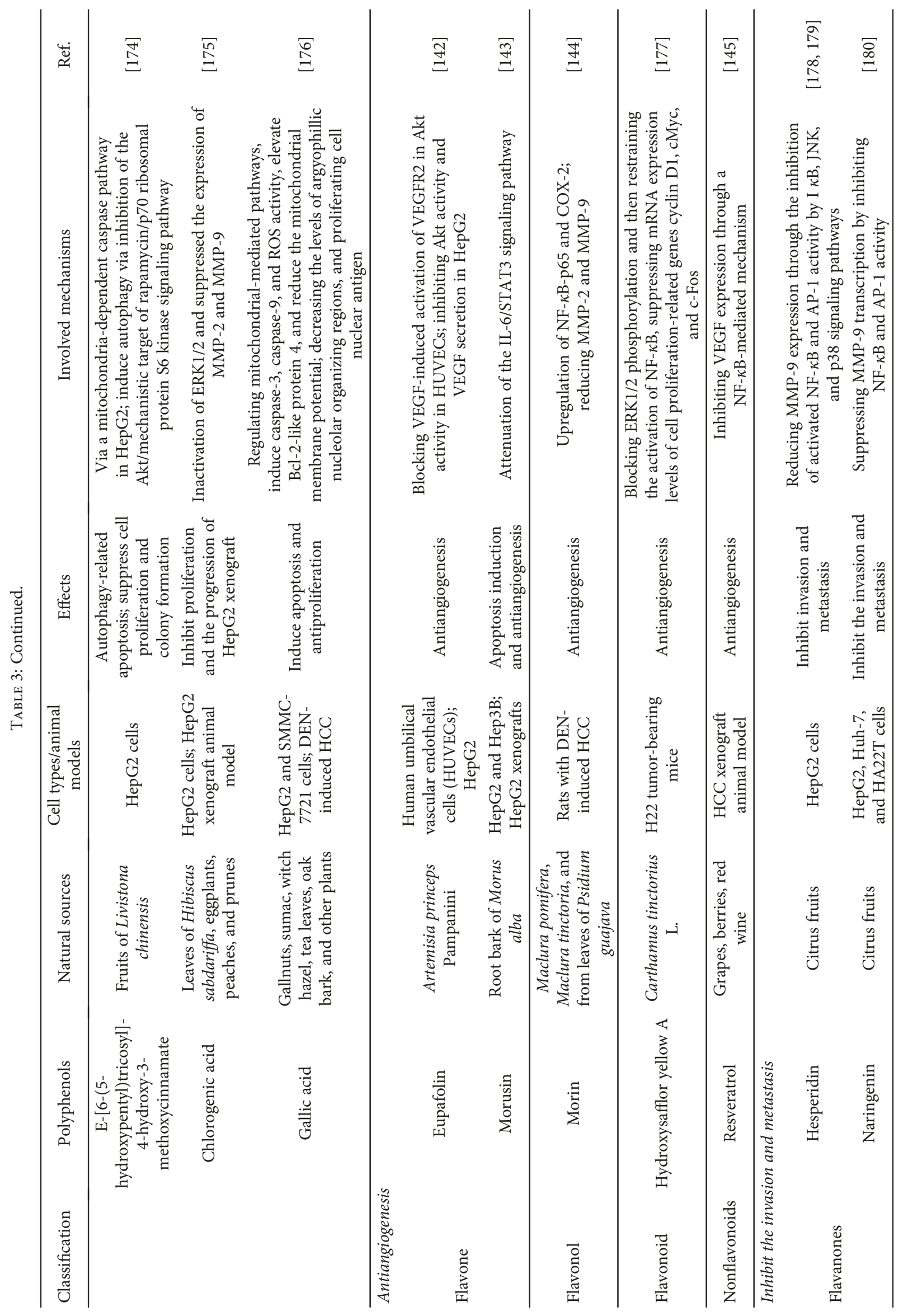




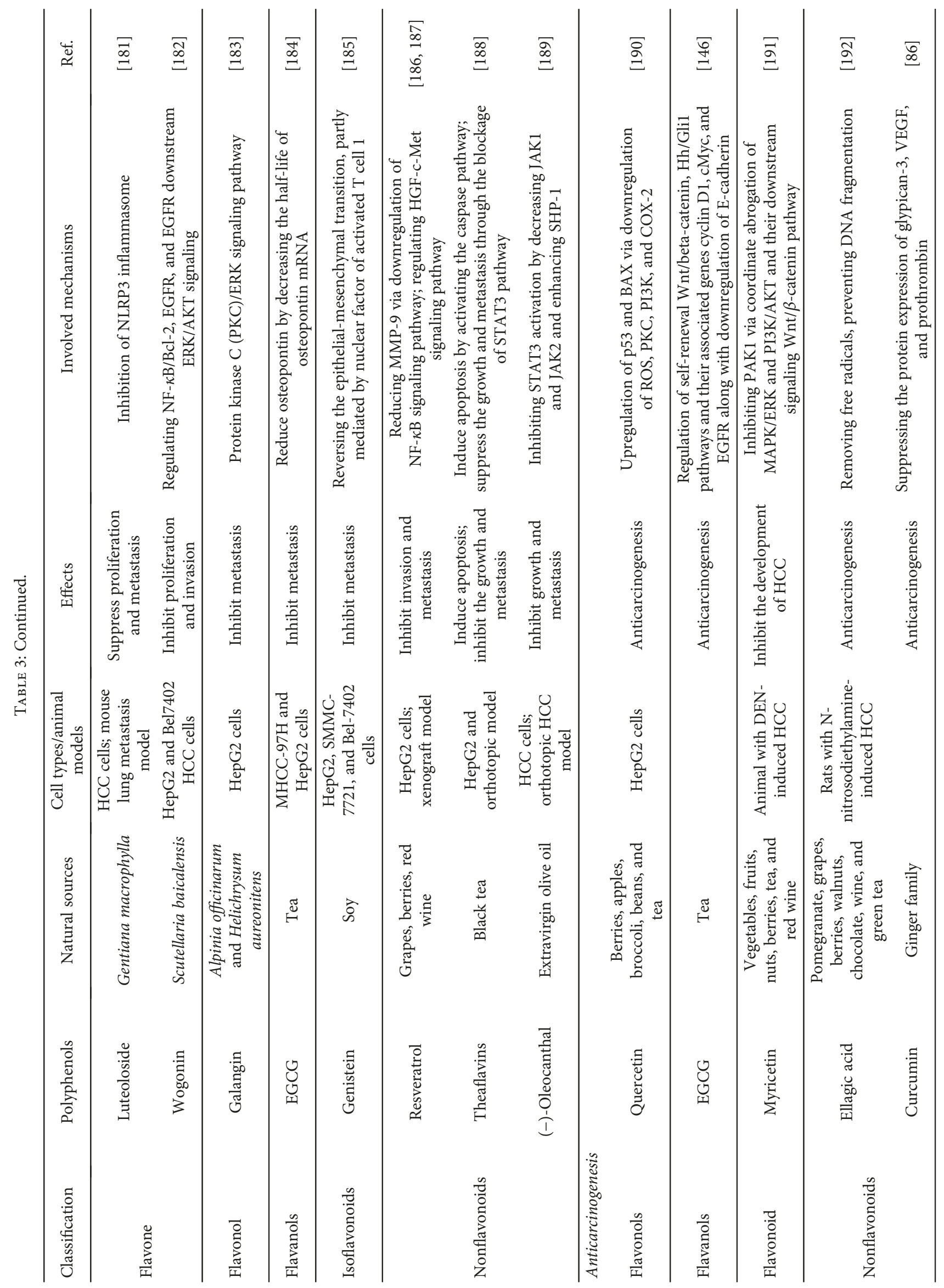


sensitize HCC cells to 5-fluorouracil treatment by inhibiting ERK activation through the overproduction of ROS [151]. Catechins enhanced the antitumor activity of doxorubicin for liver cancer involving the suppression of multidrug resistance protein 1 (MDR1) expression or accumulation increase of intracellular doxorubicin [152].

\section{Clinical Studies}

As in vitro and in vivo animal studies have revealed the promising preventive and therapeutic effects of polyphenols in various liver diseases, translational studies are extremely vital and indispensable for the application of polyphenols in human with liver diseases. Although literatures in PubMed database about clinical trials of polyphenols in liver diseases are limited, encouraging beneficial effects of these polyphenols have been demonstrated, particularly in NAFLD. In a compliant, randomized, double-blind, placebo-controlled pilot trial of purified anthocyanin in NAFLD patients, supplementation of purified anthocyanin for 12 weeks significantly improved insulin resistance, liver injury, and clinical evolution in those patients [193]. In another double-blind clinical trial, dihydromyricetin, the main active ingredient of Ampelopsis grossedentata, improved glucose and lipid metabolism and showed anti-inflammatory effects in NAFLD [194]. Intervention with green tea having highdensity catechins significantly enhanced liver function and fat infiltration in NAFLD patients in a randomized doubleblind study [195]. In particular, resveratrol, which showed extraordinary benefit for NAFLD in animal studies, has been attempted by several clinical trials. In a double-blind, randomized and placebo-controlled study, treatment with $2150 \mathrm{mg}$ resveratrol capsules twice daily for three months significantly reduced the levels of TNF- $\alpha$, cytokeratin 18 fragment, and fibroblast growth factor 21 (FGF-21) and improved adiponectin level in NAFLD patients, suggesting its beneficial role in NAFLD [196]. In another study, intervention with resveratrol at the dose of $1000 \mathrm{mg}$ daily for week 1 followed by $2000 \mathrm{mg}$ daily for week 2 significantly reduced intestinal and hepatic lipoprotein particle production in overweight/obese men [197]. However, a study claimed that resveratrol showed no benefit for patients with NAFLD. It might be due to the dosage used or intervention duration was not enough for resveratrol to exert hepatoprotective effects [198]. Additionally, intervention of orange juice with abundant flavonoids for HCV patients showed lower levels of total cholesterol and LDL-cholesterol and increased antioxidant capacity compared to that of the control group [199].

To learn about currently ongoing and unpublished studies, we further looked up the related information of clinical trials of a variety of representative polyphenols in liver diseases at the database of U.S. National Library of Medicine (http://www.ClinicalTrials.gov). The polyphenols searched are anthocyanins including delphinidin, pelargonidin, cyanidin, and malvidin; flavanols including epicatechin, epigallocatechin, EGCG, and procyanidins; flavanones including hesperidin and naringenin; flavones including apigenin, chrysin, luteolin, oroxylin A, wogonin baicalein, and isoorientin; flavonols including quercetin, kaempferol, myricetin, isorhamnetin, and galangin; isoflavonoids including genistein and daidzein; phenolic acids including ellagic acid, gallic acid, ferulic acid, and chlorogenic acid; other polyphenols including curcumin, sesamin, secoisolariciresinol diglucoside; resveratrol; pterostilbene; and piceatannol. Among them, only several compounds including curcumin, chlorogenic acid, resveratrol, EGCG, quercetin, naringenin, and catechin are found to be studied in NAFLD, HCV, cirrhosis, and liver cancer, which are listed in Table 4. Other polyphenols, which showed promising therapeutic effects on liver diseases in animal studies, such as baicalein, wogonin, kaempferol, and theaflavins, deserve to be translationally studied by clinical trials in the future.

\section{Conclusions and Prospects}

As multitude of pathways is involved in the pathogenesis of liver diseases, therapies targeting multiple factors are expected to address these driving forces for liver disease progression. Natural polyphenols, widely existing in plants and plant-based food, have attracted increasing attention as potential agents for prevention and treatment of liver diseases due to their outstanding effects on mediating pathways involved in the pathogenic process. As a matter of fact, the multiple regulations on oxidative stress, ER stress, inflammation, immune response, lipid metabolism, insulin resistance, and gut microbiota by various polyphenols are the scientific fundaments for the application of polyphenols in the prevention and treatment of liver diseases. However, although therapy by polyphenols for liver diseases has been proposed for decades and encouraging efficiency has been obtained by in vitro and in vivo studies, there is still a long way to go for the use of polyphenols in human. Several difficulties in translational research are challenging ahead. For those studies in which dose effect has been investigated, only certain polyphenols showed dose-effect manner for attenuating liver injury, suggesting the importance of determination of optimized dosage to be used. The route of administration is also a vital factor for absorption and bioavailability of polyphenols. Actually, one of the key limitations relating to the use of polyphenols is their poor bioavailability. Improving bioavailability via modification of delivery route or administration route is of great importance for translational study of polyphenols. In addition, as certain polyphenols may have side effects such as carcinogenic/genotoxic effects or disordering thyroid hormone biosynthesis, risks and safety of polyphenol consumption in liver diseases should also be well noted. It is of great importance to evaluate the doses at which these effects occur. Therefore, future studies evaluating either beneficial or adverse effects including relevant forms and doses of polyphenols should be performed. More importantly, further clinical trials are needed to evaluate the exact effects of a variety of polyphenols in patients with liver diseases, particularly for those showing remarkable therapeutic efficiency in animal study. In conclusion, a great deal of flavonoid and phenols has been demonstrated to exert multifaceted actions on various liver diseases by well-recognized mechanism, indicating their great potential in the prevention and treatment for liver diseases. In future study, the effective and safe 


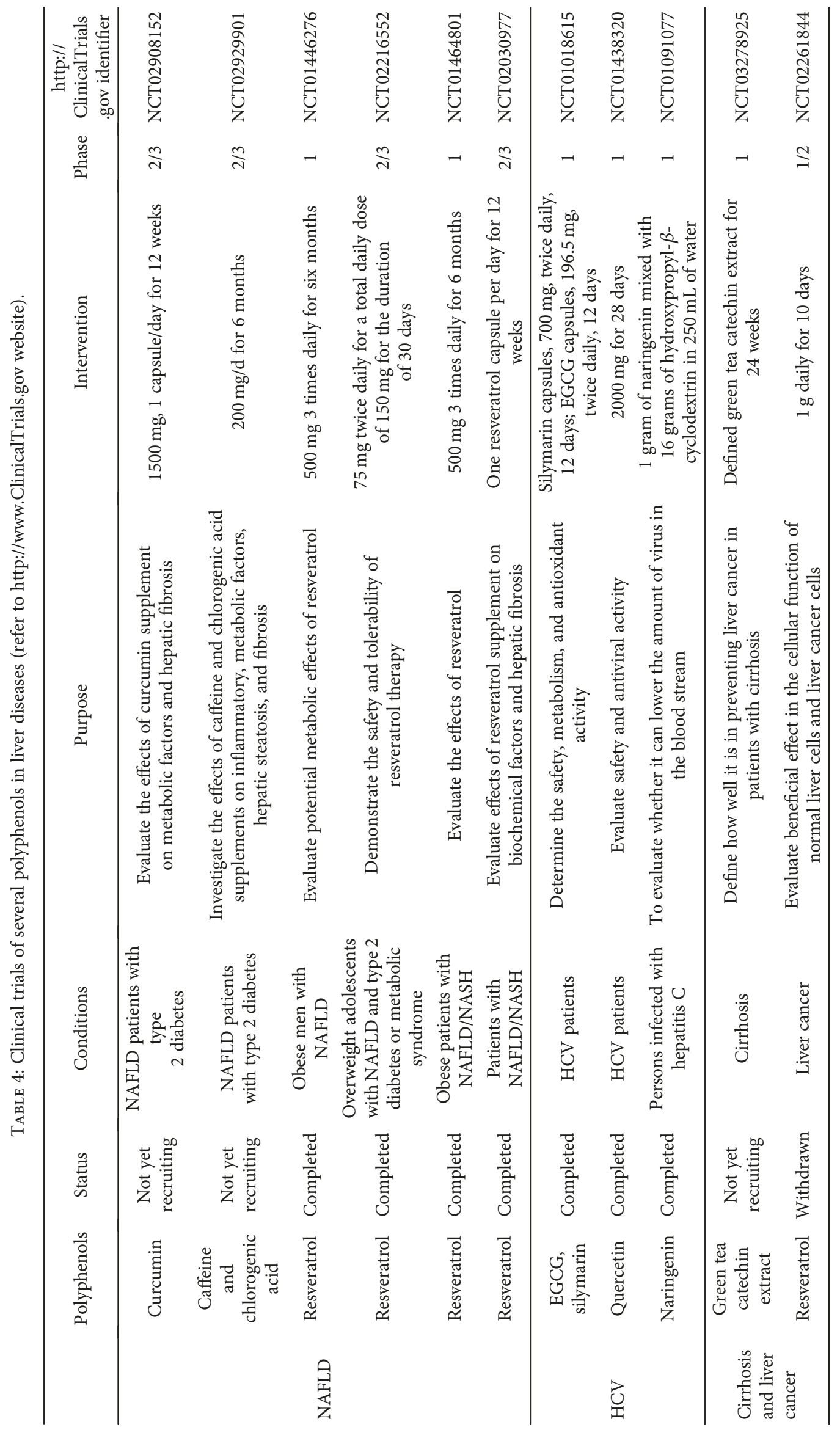


dose, duration of treatment, absorption and bioavailability of polyphenols should be thoroughly investigated from benchtop and bedside.

\section{Conflicts of Interest}

The authors declare no conflict of interest.

\section{Acknowledgments}

The study was financially supported by grants from the research council of the University of Hong Kong (Project codes 104004092, 104004460, 104003919, 104004462, 104004745, and 104004746), the Hong Kong RGC (Research Grants Committee), HKSAR (Project codes 766211 and 17152116), Gala Family Trust (Project code 200007008), Government-Matching Grant Scheme (Project code 207060411), Donation of Vita Green Health Products Co. Ltd. (Project code 200007477), and Shenzhen Basic Research Program (Project code JCYJ20140903112959964).

\section{References}

[1] S. Li, H. Y. Tan, N. Wang et al., "The role of oxidative stress and antioxidants in liver diseases," International Journal of Molecular Sciences, vol. 16, no. 11, pp. 26087-26124, 2015.

[2] S. Li, M. Hong, H. Y. Tan, N. Wang, and Y. Feng, "Insights into the role and interdependence of oxidative stress and inflammation in liver diseases," Oxidative Medicine and Cellular Longevity, vol. 2016, Article ID 4234061, 21 pages, 2016.

[3] S. L. Friedman, "Mechanisms of hepatic fibrogenesis," Gastroenterology, vol. 134, no. 6, pp. 1655-1669, 2008.

[4] F. Tacke, "Targeting hepatic macrophages to treat liver diseases," Journal of Hepatology, vol. 66, no. 6, pp. 1300-1312, 2017.

[5] G. A. Michelotti, M. V. Machado, and A. M. Diehl, "NAFLD, NASH and liver cancer," Nature Reviews Gastroenterology \& Hepatology, vol. 10, no. 11, pp. 656-665, 2013.

[6] M. Hong, S. Li, H. Tan, N. Wang, S. W. Tsao, and Y. Feng, "Current status of herbal medicines in chronic liver disease therapy: the biological effects, molecular targets and future prospects," International Journal of Molecular Sciences, vol. 16, no. 12, pp. 28705-28745, 2015.

[7] A. N. Li, S. Li, Y. J. Zhang, X. R. Xu, Y. M. Chen, and H. B. Li, "Resources and biological activities of natural polyphenols," Nutrients, vol. 6, no. 12, pp. 6020-6047, 2014.

[8] R. Domitrovic and I. Potocnjak, "A comprehensive overview of hepatoprotective natural compounds: mechanism of action and clinical perspectives," Archives of Toxicology, vol. 90, no. 1, pp. 39-79, 2016.

[9] C. Manach, A. Scalbert, C. Morand, C. Remesy, and L. Jimenez, "Polyphenols: food sources and bioavailability," The American Journal of Clinical Nutrition, vol. 79, no. 5, pp. 727-747, 2004.

[10] Y. Zhou, Y. Li, T. Zhou, J. Zheng, S. Li, and H. B. Li, "Dietary natural products for prevention and treatment of liver cancer," Nutrients, vol. 8, no. 3, p. 156, 2016.

[11] G. F. Deng, X. Lin, X. R. Xu, L. L. Gao, J. F. Xie, and H. B. Li, "Antioxidant capacities and total phenolic contents of 56 vegetables," Journal of Functional Foods, vol. 5, no. 1, pp. 260-266, 2013.
[12] L. Fu, B. T. Xu, X. R. Xu et al., "Antioxidant capacities and total phenolic contents of 62 fruits," Food Chemistry, vol. 129, no. 2, pp. 345-350, 2011.

[13] G. F. Deng, X. R. Xu, Y. J. Guo et al., "Determination of antioxidant property and their lipophilic and hydrophilic phenolic contents in cereal grains," Journal of Functional Foods, vol. 4, no. 4, pp. 906-914, 2012.

[14] B. Shan, Y. Z. Cai, M. Sun, and H. Corke, "Antioxidant capacity of 26 spice extracts and characterization of their phenolic constituents," Journal of Agricultural and Food Chemistry, vol. 53, no. 20, pp. 7749-7759, 2005.

[15] Y. J. Guo, G. F. Deng, X. R. Xu et al., “Antioxidant capacities, phenolic compounds and polysaccharide contents of 49 edible macro-fungi," Food \& Function, vol. 3, no. 11, pp. 1195-1205, 2012.

[16] L. Zeng, L. Luo, H. Li, and R. Liu, "Phytochemical profiles and antioxidant activity of 27 cultivars of tea," International Journal of Food Sciences and Nutrition, vol. 68, no. 5, pp. 525-537, 2016.

[17] H. Li, K. Cheng, C. Wong, K. Fan, F. Chen, and Y. Jiang, "Evaluation of antioxidant capacity and total phenolic content of different fractions of selected microalgae," Food Chemistry, vol. 102, no. 3, pp. 771-776, 2007.

[18] S. Li, S. K. Li, R. Y. Gan, F. L. Song, L. Kuang, and H. B. Li, "Antioxidant capacities and total phenolic contents of infusions from 223 medicinal plants," Industrial Crops and Products, vol. 51, pp. 289-298, 2013.

[19] L. Fu, B. T. Xu, X. R. Xu, X. S. Qin, R. Y. Gan, and H. B. Li, "Antioxidant capacities and total phenolic contents of 56 wild fruits from South China," Molecules, vol. 15, no. 12, pp. 8602$8617,2010$.

[20] A. N. Li, S. Li, H. B. Li, D. P. Xu, X. R. Xu, and F. Chen, "Total phenolic contents and antioxidant capacities of 51 edible and wild flowers," Journal of Functional Foods, vol. 6, pp. 319-330, 2014.

[21] G. F. Deng, C. Shen, X. R. Xu et al., "Potential of fruit wastes as natural resources of bioactive compounds," International Journal of Molecular Sciences, vol. 13, no. 12, pp. 83088323, 2012.

[22] G. Malaguarnera, E. Cataudella, M. Giordano, G. Nunnari, G. Chisari, and M. Malaguarnera, "Toxic hepatitis in occupational exposure to solvents," World Journal of Gastroenterology, vol. 18, no. 22, pp. 2756-2766, 2012.

[23] J. Q. Ma, Z. Li, W. R. Xie, C. M. Liu, and S. S. Liu, "Quercetin protects mouse liver against $\mathrm{CCl}_{4}$-induced inflammation by the TLR2/4 and MAPK/NF- $\kappa \mathrm{B}$ pathway," International Immunopharmacology, vol. 28, no. 1, pp. 531-539, 2015.

[24] J. Q. Ma, J. Ding, H. Zhao, and C. M. Liu, "Puerarin attenuates carbon tetrachloride-induced liver oxidative stress and hyperlipidaemia in mouse by JNK/c-Jun/CYP7A1 pathway," Basic \& Clinical Pharmacology \& Toxicology, vol. 115, no. 5, pp. 389-395, 2014.

[25] M. C. Kang, S. M. Kang, G. Ahn et al., "Protective effect of a marine polyphenol, dieckol against carbon tetrachlorideinduced acute liver damage in mouse," Environmental Toxicology and Pharmacology, vol. 35, no. 3, pp. 517-523, 2013.

[26] D. W. Kim, H. I. Cho, K. M. Kim et al., "Isorhamnetin-3$\mathrm{O}$-galactoside protects against $\mathrm{CCl}_{4}$-induced hepatic injury in mice," Biomolecules \& Therapeutics, vol. 20, no. 4, pp. 406-412, 2012. 
[27] S. Zhang, B. Lu, X. Han et al., "Protection of the flavonoid fraction from Rosa laevigata Michx fruit against carbon tetrachloride-induced acute liver injury in mice," Food and Chemical Toxicology, vol. 55, pp. 60-69, 2013.

[28] C. C. Liao, Y. J. Day, H. C. Lee, J. T. Liou, A. H. Chou, and F. C. Liu, "ERK signaling pathway plays a key role in baicalin protection against acetaminophen-induced liver injury," The American Journal of Chinese Medicine, vol. 45, no. 01, pp. 105-121, 2017.

[29] H. Wu, G. Zhang, L. Huang et al., "Hepatoprotective effect of polyphenol-enriched fraction from Folium Microcos on oxidative stress and apoptosis in acetaminophen-induced liver injury in mice," Oxidative Medicine and Cellular Longevity, vol. 2017, Article ID 3631565, 14 pages, 2017.

[30] C. H. Lee, C. Y. Kuo, C. J. Wang et al., "A polyphenol extract of Hibiscus sabdariffa L. ameliorates acetaminophen-induced hepatic steatosis by attenuating the mitochondrial dysfunction in vivo and in vitro," Bioscience, Biotechnology, and Biochemistry, vol. 76, no. 4, pp. 646-651, 2012.

[31] Z. He, X. Li, H. Chen et al., "Nobiletin attenuates lipopolysaccharide/D-galactosamine-induced liver injury in mice by activating the Nrf2 antioxidant pathway and subsequently inhibiting NF- $\kappa \mathrm{B}$-mediated cytokine production," Molecular Medicine Reports, vol. 14, no. 6, pp. 5595-5600, 2016.

[32] W. Zhong, K. Qian, J. Xiong, K. Ma, A. Wang, and Y. Zou, "Curcumin alleviates lipopolysaccharide induced sepsis and liver failure by suppression of oxidative stress-related inflammation via PI3K/AKT and NF- $\kappa$ B related signaling," Biomedicine \& Pharmacotherapy, vol. 83, pp. 302-313, 2016.

[33] M. Zaulet, S. E. M. Kevorkian, S. Dinescu et al., "Protective effects of silymarin against bisphenol A-induced hepatotoxicity in mouse liver," Experimental and Therapeutic Medicine, vol. 13, no. 3, pp. 821-828, 2017.

[34] S. H. Seif El-Din, N. M. El-Lakkany, M. B. Salem, O. A. Hammam, S. Saleh, and S. S. Botros, "Resveratrol mitigates hepatic injury in rats by regulating oxidative stress, nuclear factorkappa B, and apoptosis," Journal of Advanced Pharmaceutical Technology \& Research, vol. 7, no. 3, pp. 99-104, 2016.

[35] A. Louvet and P. Mathurin, "Alcoholic liver disease: mechanisms of injury and targeted treatment," Nature Reviews Gastroenterology \& Hepatology, vol. 12, no. 4, pp. 231-242, 2015.

[36] C. M. Hu, Q. Cao, X. W. Lv, W. M. Cheng, R. Li, and J. Li, "Protective effects of total flavonoids from Litsea coreana on alcoholic fatty liver in rats associated with down-regulation adipose differentiation-related protein expression," The American Journal of Chinese Medicine, vol. 40, no. 03, pp. 599-610, 2012.

[37] Q. Sun, W. Zhang, W. Zhong, X. Sun, and Z. Zhou, "Dietary fisetin supplementation protects against alcohol-induced liver injury in mice," Alcoholism, Clinical \& Experimental Research, vol. 40, no. 10, pp. 2076-2084, 2016.

[38] B. K. Choi, T. W. Kim, D. R. Lee et al., "A polymethoxy flavonoids-rich Citrus aurantium extract ameliorates ethanol-induced liver injury through modulation of AMPK and Nrf2-related signals in a binge drinking mouse model," Phytotherapy Research, vol. 29, no. 10, pp. 1577-1584, 2015.

[39] G. Liu, Y. Zhang, C. Liu et al., "Luteolin alleviates alcoholic liver disease induced by chronic and binge ethanol feeding in mice," The Journal of Nutrition, vol. 144, no. 7, pp. 10091015, 2014.

[40] Z. Wang, B. Su, S. Fan, H. Fei, and W. Zhao, "Protective effect of oligomeric proanthocyanidins against alcohol-induced liver steatosis and injury in mice," Biochemical and Biophysical Research Communications, vol. 458, no. 4, pp. 757-762, 2015.

[41] H. Yamashita, M. Goto, I. Matsui-Yuasa, and A. KojimaYuasa, "Ecklonia cava polyphenol has a protective effect against ethanol-induced liver injury in a cyclic AMPdependent manner," Marine Drugs, vol. 13, no. 6, pp. 38773891, 2015.

[42] J. S. Londhe, T. P. A. Devasagayam, L. Y. Foo, P. Shastry, and S. S. Ghaskadbi, "Geraniin and amariin, ellagitannins from Phyllanthus amarus, protect liver cells against ethanol induced cytotoxicity," Fitoterapia, vol. 83, no. 8, pp. 1562 1568, 2012.

[43] R. Yao, A. Yasuoka, A. Kamei et al., "Nuclear receptormediated alleviation of alcoholic fatty liver by polyphenols contained in alcoholic beverages," PLoS One, vol. 9, no. 2, article e87142, 2014

[44] S. Milic, I. Mikolasevic, L. Orlic et al., "The role of iron and iron overload in chronic liver disease," Medical Science Monitor, vol. 22, pp. 2144-2151, 2016.

[45] Y. Ren, F. Deng, H. Zhu, W. Wan, J. Ye, and B. Luo, "Effect of epigallocatechin-3-gallate on iron overload in mice with alcoholic liver disease," Molecular Biology Reports, vol. 38, no. 2, pp. 879-886, 2011.

[46] L. Zeng, W. J. Tang, J. J. Yin, and B. J. Zhou, "Signal transductions and nonalcoholic fatty liver: a mini-review," International Journal of Clinical and Experimental Medicine, vol. 7, no. 7, pp. 1624-1631, 2014.

[47] B. Van De Wier, G. H. Koek, A. Bast, and G. R. M. M. Haenen, "The potential of flavonoids in the treatment of non-alcoholic fatty liver disease," Critical Reviews in Food Science and Nutrition, vol. 57, no. 4, pp. 834-855, 2017.

[48] C. Luo, H. Yang, C. Tang et al., "Kaempferol alleviates insulin resistance via hepatic IKK/NF- $\kappa \mathrm{B}$ signal in type 2 diabetic rats," International Immunopharmacology, vol. 28, no. 1, pp. 744-750, 2015.

[49] L. M. Jimenez-Flores, S. Lopez-Briones, M. H. MaciasCervantes, J. Ramirez-Emiliano, and V. Perez-Vazquez, "A $\operatorname{PPAR} \gamma, \mathrm{NF}-\kappa \mathrm{B}$ and AMPK-dependent mechanism may be involved in the beneficial effects of curcumin in the diabetic db/db mice liver," Molecules, vol. 19, no. 6, pp. 8289-8302, 2014.

[50] X. Wang, D. M. Zhang, T. T. Gu et al., "Morin reduces hepatic inflammation-associated lipid accumulation in high fructose-fed rats via inhibiting sphingosine kinase 1/sphingosine 1-phosphate signaling pathway," Biochemical Pharmacology, vol. 86, no. 12, pp. 1791-1804, 2013.

[51] J. S. Noh, C. H. Park, and T. Yokozawa, "Treatment with oligonol, a low-molecular polyphenol derived from lychee fruit, attenuates diabetes-induced hepatic damage through regulation of oxidative stress and lipid metabolism," The British Journal of Nutrition, vol. 106, no. 07, pp. 1013-1022, 2011.

[52] D. Porras, E. Nistal, S. Martínez-Flórez et al., "Protective effect of quercetin on high-fat diet-induced non-alcoholic fatty liver disease in mice is mediated by modulating intestinal microbiota imbalance and related gut-liver axis activation," Free Radical Biology \& Medicine, vol. 102, pp. 188-202, 2017.

[53] Z. R. Xu, J. Y. Li, X. W. Dong et al., "Apple polyphenols decrease atherosclerosis and hepatic steatosis in $\mathrm{ApoE}^{-1-}$ mice through the ROS/MAPK/NF- $\kappa \mathrm{B}$ pathway," Nutrients, vol. 7, no. 8, pp. 7085-7105, 2015. 
[54] I. Cordero-Herrera, M. A. Martin, L. Goya, and S. Ramos, "Cocoa flavonoids protect hepatic cells against highglucose-induced oxidative stress: relevance of MAPKs," Molecular Nutrition \& Food Research, vol. 59, no. 4, pp. 597-609, 2015.

[55] S. Medjakovic, M. Mueller, and A. Jungbauer, "Potential health-modulating effects of isoflavones and metabolites via activation of PPAR and AhR," Nutrients, vol. 2, no. 3, pp. 241-279, 2010.

[56] Y. Jia, J. Y. Kim, H. J. Jun et al., "Cyanidin is an agonistic ligand for peroxisome proliferator-activated receptor-alpha reducing hepatic lipid," Biochimica et Biophysica Acta (BBA) - Molecular and Cell Biology of Lipids, vol. 1831, no. 4, pp. 698-708, 2013.

[57] C. Chang, T. F. Tzeng, S. S. Liou, Y. S. Chang, and I. M. Liu, "Kaempferol regulates the lipid-profile in high-fat diet-fed rats through an increase in hepatic PPAR $\alpha$ levels," Planta Medica, vol. 77, no. 17, pp. 1876-1882, 2011.

[58] J. Goldwasser, P. Y. Cohen, E. Yang, P. Balaguer, M. L. Yarmush, and Y. Nahmias, "Transcriptional regulation of human and rat hepatic lipid metabolism by the grapefruit flavonoid naringenin: role of PPAR $\alpha$, PPAR $\gamma$ and LXR $\alpha$," PLoS One, vol. 5, no. 8, article e12399, 2010.

[59] T. Goto, A. Teraminami, J. Y. Lee et al., "Tiliroside, a glycosidic flavonoid, ameliorates obesity-induced metabolic disorders via activation of adiponectin signaling followed by enhancement of fatty acid oxidation in liver and skeletal muscle in obese-diabetic mice," The Journal of Nutritional Biochemistry, vol. 23, no. 7, pp. 768-776, 2012.

[60] J. W. Lee, S. S. Choe, H. Jang et al., "AMPK activation with glabridin ameliorates adiposity and lipid dysregulation in obesity," Journal of Lipid Research, vol. 53, no. 7, pp. 1277-1286, 2012.

[61] X. Yang, Q. Wang, Z. R. Pang, M. R. Pan, and W. Zhang, "Flavonoid-enriched extract from Hippophae rhamnoides seed reduces high fat diet induced obesity, hypertriglyceridemia, and hepatic triglyceride accumulation in C57BL/6 mice," Pharmaceutical Biology, vol. 55, no. 1, pp. 12071214, 2017.

[62] E. S. Shin, H. H. Lee, S. Y. Cho, H. W. Park, S. J. Lee, and T. R. Lee, "Genistein downregulates SREBP-1 regulated gene expression by inhibiting site-1 protease expression in HepG2 cells," The Journal of Nutrition, vol. 137, no. 5, pp. 1127-1131, 2007.

[63] J. F. Liu, Y. Ma, Y. Wang, Z. Y. Du, J. K. Shen, and H. L. Peng, "Reduction of lipid accumulation in HepG2 cells by luteolin is associated with activation of AMPK and mitigation of oxidative stress," Phytotherapy Research, vol. 25, no. 4, pp. 588-596, 2011.

[64] C. H. Wu, M. C. Lin, H. C. Wang, M. Y. Yang, M. J. Jou, and C. J. Wang, "Rutin inhibits oleic acid induced lipid accumulation via reducing lipogenesis and oxidative stress in hepatocarcinoma cells," Journal of Food Science, vol. 76, no. 2, pp. T65-T72, 2011.

[65] T. G. Ahn, G. Yang, H. M. Lee et al., "Molecular mechanisms underlying the anti-obesity potential of prunetin, an $O$-methylated isoflavone," Biochemical Pharmacology, vol. 85, no. 10, pp. 1525-1533, 2013.

[66] P. Ferre and F. Foufelle, "Hepatic steatosis: a role for de novo lipogenesis and the transcription factor SREBP-1c," Diabetes, Obesity \& Metabolism, vol. 12, Supplement 2, pp. 83-92, 2010.
[67] Y. J. Choi, H. R. Suh, Y. Yoon et al., "Protective effect of resveratrol derivatives on high-fat diet induced fatty liver by activating AMP-activated protein kinase," Archives of Pharmacal Research, vol. 37, no. 9, pp. 1169-1176, 2014.

[68] Z. Li, J. Xu, P. Zheng et al., "Hawthorn leaf flavonoids alleviate nonalcoholic fatty liver disease by enhancing the adiponectin/AMPK pathway," International Journal of Clinical and Experimental Medicine, vol. 8, no. 10, pp. 17295-17307, 2015.

[69] E. H. Jung, J. H. Lee, S. C. Kim, and Y. W. Kim, “AMPK activation by liquiritigenin inhibited oxidative hepatic injury and mitochondrial dysfunction induced by nutrition deprivation as mediated with induction of farnesoid X receptor," European Journal of Nutrition, vol. 56, no. 2, pp. 635-647, 2017.

[70] Y. M. Yang, S. Y. Seo, T. H. Kim, and S. G. Kim, "Decrease of microRNA-122 causes hepatic insulin resistance by inducing protein tyrosine phosphatase $1 \mathrm{~B}$, which is reversed by licorice flavonoid," Hepatology, vol. 56, no. 6, pp. 2209-2220, 2012.

[71] L. Baselga-Escudero, A. Pascual-Serrano, A. Ribas-Latre et al., "Long-term supplementation with a low dose of proanthocyanidins normalized liver miR-33a and miR-122 levels in high-fat diet-induced obese rats," Nutrition Research, vol. 35, no. 4, pp. 337-345, 2015.

[72] J. Joven, E. Espinel, A. Rull et al., "Plant-derived polyphenols regulate expression of miRNA paralogs miR-103/107 and miR-122 and prevent diet-induced fatty liver disease in hyperlipidemic mice," Biochimica et Biophysica Acta (BBA) - General Subjects, vol. 1820, no. 7, pp. 894-899, 2012

[73] D. Su, R. Zhang, F. Hou et al., "Lychee pulp phenolics ameliorate hepatic lipid accumulation by reducing miR-33 and miR-122 expression in mice fed a high-fat diet," Food \& Function, vol. 8, no. 2, pp. 808-815, 2017.

[74] C. Leung, L. Rivera, J. B. Furness, and P. W. Angus, "The role of the gut microbiota in NAFLD," Nature Reviews Gastroenterology \& Hepatology, vol. 13, no. 7, pp. 412-425, 2016.

[75] V. J. Lavallard and P. Gual, "Autophagy and non-alcoholic fatty liver disease," BioMed Research International, vol. 2014, Article ID 120179, 13 pages, 2014.

[76] M. Parafati, A. Lascala, V. M. Morittu et al., "Bergamot polyphenol fraction prevents nonalcoholic fatty liver disease via stimulation of lipophagy in cafeteria diet-induced rat model of metabolic syndrome," The Journal of Nutritional Biochemistry, vol. 26, no. 9, pp. 938-948, 2015.

[77] M. E. Inzaugarat, E. De Matteo, P. Baz et al., "New evidence for the therapeutic potential of curcumin to treat nonalcoholic fatty liver disease in humans," PLoS One, vol. 12, no. 3, article e0172900, 2017.

[78] C. S. Kim, H. S. Choi, Y. Joe, H. T. Chung, and R. Yu, "Induction of heme oxygenase-1 with dietary quercetin reduces obesity-induced hepatic inflammation through macrophage phenotype switching," Nutrition Research and Practice, vol. 10, no. 6, pp. 623-628, 2016.

[79] L. Wang, B. Zhang, F. Huang, B. Liu, and Y. Xie, "Curcumin inhibits lipolysis via suppression of ER stress in adipose tissue and prevents hepatic insulin resistance," Journal of Lipid Research, vol. 57, no. 7, pp. 1243-1255, 2016.

[80] E. Zhang, S. Yin, X. Song, L. Fan, and H. Hu, "Glycycoumarin inhibits hepatocyte lipoapoptosis through activation of autophagy and inhibition of ER stress/GSK-3-mediated 
mitochondrial pathway," Scientific Reports, vol. 6, no. 1, article 38138, 2016.

[81] L. Méndez, S. Ciordia, M. S. Fernández et al., "Changes in liver proteins of rats fed standard and high-fat and sucrose diets induced by fish omega-3 PUFAs and their combination with grape polyphenols according to quantitative proteomics," The Journal of Nutritional Biochemistry, vol. 41, pp. 84-97, 2017.

[82] R. Patil and G. K. Sood, "Non-alcoholic fatty liver disease and cardiovascular risk," World Journal of Gastrointestinal Pathophysiology, vol. 8, no. 2, pp. 51-58, 2017.

[83] S. M. Francque, D. van der Graaff, and W. J. Kwanten, "Nonalcoholic fatty liver disease and cardiovascular risk: pathophysiological mechanisms and implications," Journal of Hepatology, vol. 65, no. 2, pp. 425-443, 2016.

[84] L. Polimeni, M. Del Ben, F. Baratta et al., "Oxidative stress: new insights on the association of non-alcoholic fatty liver disease and atherosclerosis," World Journal of Hepatology, vol. 7, no. 10, pp. 1325-1336, 2015.

[85] J. Tomé-Carneiro, M. Gonzálvez, M. Larrosa et al., "Resveratrol in primary and secondary prevention of cardiovascular disease: a dietary and clinical perspective," Annals of the New York Academy of Sciences, vol. 1290, no. 1, pp. 37-51, 2013.

[86] R. Afrin, S. Arumugam, A. Rahman et al., "Curcumin ameliorates liver damage and progression of NASH in NASH-HCC mouse model possibly by modulating HMGB1-NF- $\kappa \mathrm{B}$ translocation," International Immunopharmacology, vol. 44, pp. 174-182, 2017.

[87] Y. B. Zhang, L. Q. Zhan, G. Q. Li et al., "Dimeric matrine-type alkaloids from the roots of sophora flavescens and their antihepatitis B virus activities," The Journal of Organic Chemistry, vol. 81, no. 15, pp. 6273-6280, 2016.

[88] W. Xiong, X. Ma, Y. Wu et al., "Determine the structure of phosphorylated modification of icariin and its antiviral activity against duck hepatitis virus A," BMC Veterinary Research, vol. 11, no. 1, p. 205, 2015.

[89] M. K. Parvez, A. H. Arbab, M. S. Al-Dosari, and A. J. Al-Rehaily, "Antiviral natural products against chronic hepatitis B: recent developments," Current Pharmaceutical Design, vol. 22, no. 3, pp. 286-293, 2016.

[90] H. C. Huang, M. H. Tao, T. M. Hung, J. C. Chen, Z. J. Lin, and C. Huang, "(-)-Epigallocatechin-3-gallate inhibits entry of hepatitis B virus into hepatocytes," Antiviral Research, vol. 111, pp. 100-111, 2014.

[91] N. Calland, A. Albecka, S. Belouzard et al., "(-)-Epigallocatechin-3-gallate is a new inhibitor of hepatitis C virus entry," Hepatology, vol. 55, no. 3, pp. 720-729, 2012.

[92] S. Ciesek, T. von Hahn, C. C. Colpitts et al., "The green tea polyphenol, epigallocatechin-3-gallate, inhibits hepatitis C virus entry," Hepatology, vol. 54, no. 6, pp. 1947-1955, 2011.

[93] N. Calland, M. E. Sahuc, S. Belouzard et al., "Polyphenols inhibit hepatitis $C$ virus entry by a new mechanism of action," Journal of Virology, vol. 89, no. 19, pp. 10053-10063, 2015.

[94] S. Liu, R. Chen, and C. H. Hagedorn, "Tannic acid inhibits hepatitis C virus entry into Huh7.5 cells," PLoS One, vol. 10, no. 7, article e0131358, 2015.

[95] A. Ahmed-Belkacem, N. Ahnou, L. Barbotte et al., "Silibinin and related compounds are direct inhibitors of hepatitis $\mathrm{C}$ virus RNA-dependent RNA polymerase," Gastroenterology, vol. 138, no. 3, pp. 1112-1122, 2010.
[96] Y. T. Lin, Y. H. Wu, C. K. Tseng et al., “Green tea phenolic epicatechins inhibit hepatitis C virus replication via cycloxygenase- 2 and attenuate virus-induced inflammation," PLoS One, vol. 8, no. 1, article e54466, 2013.

[97] C. Shibata, M. Ohno, M. Otsuka et al., "The flavonoid apigenin inhibits hepatitis $\mathrm{C}$ virus replication by decreasing mature microRNA122 levels," Virology, vol. 462-463, pp. 42-48, 2014.

[98] M. M. Rechtman, O. Har-Noy, I. Bar-Yishay et al., "Curcumin inhibits hepatitis $\mathrm{B}$ virus via down-regulation of the metabolic coactivator PGC-1 $\alpha$," FEBS Letters, vol. 584, no. 11, pp. 2485-2490, 2010.

[99] Y. Chen, L. Zeng, J. Yang et al., "Anti-DHAV-1 reproduction and immuno-regulatory effects of a flavonoid prescription on duck virus hepatitis," Pharmaceutical Biology, vol. 55, no. 1, pp. 1545-1552, 2017.

[100] A. Rojas, J. A. Del Campo, S. Clement et al., "Effect of quercetin on hepatitis C virus life cycle: from viral to host targets," Scientific Reports, vol. 6, no. 1, article 31777, 2016.

[101] A. Furuta, M. Tsubuki, M. Endoh et al., "Identification of hydroxyanthraquinones as novel inhibitors of hepatitis $\mathrm{C}$ virus NS3 helicase," International Journal of Molecular Sciences, vol. 16, no. 8, pp. 18439-18453, 2015.

[102] L. Bachmetov, M. Gal-Tanamy, A. Shapira et al., "Suppression of hepatitis $\mathrm{C}$ virus by the flavonoid quercetin is mediated by inhibition of NS3 protease activity," Journal of Viral Hepatitis, vol. 19, no. 2, pp. e81-e88, 2012.

[103] C. Roh and S. K. Jo, "(-)-Epigallocatechin gallate inhibits hepatitis C virus (HCV) viral protein NS5B," Talanta, vol. 85, no. 5, pp. 2639-2642, 2011.

[104] Y. Zhao, C. A. Geng, Y. B. Ma et al., "UFLC/MS-IT-TOF guided isolation of anti-HBV active chlorogenic acid analogues from Artemisia capillaris as a traditional Chinese herb for the treatment of hepatitis," Journal of Ethnopharmacology, vol. 156, pp. 147-154, 2014.

[105] Y. Sekine-Osajima, N. Sakamoto, M. Nakagawa et al., "Two flavonoids extracts from Glycyrrhizae radix inhibit in vitro hepatitis C virus replication," Hepatology Research, vol. 39, no. 1, pp. 60-69, 2009.

[106] M. Adianti, C. Aoki, M. Komoto et al., "Anti-hepatitis C virus compounds obtained from Glycyrrhiza uralensis and other Glycyrrhiza species," Microbiology and Immunology, vol. 58, no. 3, pp. 180-187, 2014.

[107] D. F. Hicks, N. Goossens, A. Blas-García et al., "Transcriptome-based repurposing of apigenin as a potential antifibrotic agent targeting hepatic stellate cells," Scientific Reports, vol. 7, article 42563, 2017.

[108] M. L. Arffa, M. A. Zapf, A. N. Kothari et al., "Epigallocatechin-3-Gallate upregulates miR-221 to inhibit osteopontindependent hepatic fibrosis," PLoS One, vol. 11, no. 12, article e0167435, 2016.

[109] L. D. Hernández-Ortega, B. E. Alcántar-Díaz, L. A. RuizCorro et al., "Quercetin improves hepatic fibrosis reducing hepatic stellate cells and regulating pro-fibrogenic/anti-fibrogenic molecules balance," Journal of Gastroenterology and Hepatology, vol. 27, no. 12, pp. 1865-1872, 2012.

[110] J. Li, P. Liu, R. Zhang et al., "Icaritin induces cell death in activated hepatic stellate cells through mitochondrial activated apoptosis and ameliorates the development of liver fibrosis in rats," Journal of Ethnopharmacology, vol. 137, no. 1, pp. 714-723, 2011. 
[111] J. Qiu, Q. Zhou, X. Zhai, X. Jia, and Y. Zhou, "Curcumin regulates delta-like homolog 1 expression in activated hepatic stellate cell," European Journal of Pharmacology, vol. 728, pp. 9-15, 2014.

[112] J. Lin and A. Chen, "Curcumin diminishes the impacts of hyperglycemia on the activation of hepatic stellate cells by suppressing membrane translocation and gene expression of glucose transporter-2," Molecular and Cellular Endocrinology, vol. 333, no. 2, pp. 160-171, 2011.

[113] A. Ahmad and R. Ahmad, "Resveratrol mitigate structural changes and hepatic stellate cell activation in $N^{\prime}$-nitrosodimethylamine-induced liver fibrosis via restraining oxidative damage," Chemico-Biological Interactions, vol. 221, pp. 1-12, 2014.

[114] Y. J. Chang, S. L. Hsu, Y. T. Liu et al., "Gallic acid induces necroptosis via TNF- $\alpha$ signaling pathway in activated hepatic stellate cells," PLoS One, vol. 10, no. 3, article e0120713, 2015.

[115] L. He, X. Hou, F. Fan, and H. Wu, "Quercetin stimulates mitochondrial apoptosis dependent on activation of endoplasmic reticulum stress in hepatic stellate cells," Pharmaceutical Biology, vol. 54, no. 12, pp. 3237-3243, 2016.

[116] C. Balta, H. Herman, O. M. Boldura et al., "Chrysin attenuates liver fibrosis and hepatic stellate cell activation through TGF- $\beta$ /Smad signaling pathway," Chemico-Biological Interactions, vol. 240, pp. 94-101, 2015.

[117] N. Seki, U. Toh, K. Kawaguchi et al., "Tricin inhibits proliferation of human hepatic stellate cells in vitro by blocking tyrosine phosphorylation of PDGF receptor and its signaling pathways," Journal of Cellular Biochemistry, vol. 113, no. 7, pp. 2346-2355, 2012.

[118] H. Shi, A. Shi, L. Dong et al., "Chlorogenic acid protects against liver fibrosis in vivo and in vitro through inhibition of oxidative stress," Clinical Nutrition, vol. 35, no. 6, pp. 1366-1373, 2016.

[119] H. Zhang, Q. Sun, T. Xu et al., "Resveratrol attenuates the progress of liver fibrosis via the Akt/nuclear factor- $\kappa \mathrm{B}$ pathways," Molecular Medicine Reports, vol. 13, no. 1, pp. 224230, 2016.

[120] D. K. Yu, C. X. Zhang, S. S. Zhao et al., "The anti-fibrotic effects of epigallocatechin-3-gallate in bile duct-ligated cholestatic rats and human hepatic stellate LX-2 cells are mediated by the PI3K/Akt/Smad pathway," Acta Pharmacologica Sinica, vol. 36, no. 4, pp. 473-482, 2015.

[121] Q. Wang, R. Wen, Q. Lin, N. Wang, P. Lu, and X. Zhu, "Wogonoside shows antifibrotic effects in an experimental regression model of hepatic fibrosis," Digestive Diseases and Sciences, vol. 60, no. 11, pp. 3329-3339, 2015.

[122] G. H. Heeba and M. E. Mahmoud, "Therapeutic potential of morin against liver fibrosis in rats: modulation of oxidative stress, cytokine production and nuclear factor kappa B," Environmental Toxicology and Pharmacology, vol. 37, no. 2, pp. 662-671, 2014.

[123] H. Shi, L. Dong, J. Jiang et al., "Chlorogenic acid reduces liver inflammation and fibrosis through inhibition of toll-like receptor 4 signaling pathway," Toxicology, vol. 303, pp. 107-114, 2013.

[124] B. Stefanska, "Curcumin ameliorates hepatic fibrosis in type 2 diabetes mellitus - insights into its mechanisms of action," British Journal of Pharmacology, vol. 166, no. 8, pp. 22092211, 2012.
[125] L. Wang, Z. Yue, M. Guo et al., "Dietary flavonoid hyperoside induces apoptosis of activated human LX-2 hepatic stellate cell by suppressing canonical NF- $\kappa \mathrm{B}$ signaling," BioMed Research International, vol. 2016, Article ID 1068528, 10 pages, 2016.

[126] J. Li, X. Li, W. Xu et al., "Antifibrotic effects of luteolin on hepatic stellate cells and liver fibrosis by targeting AKT/ mTOR/p70S6K and TGF $\beta /$ Smad signalling pathways," Liver International, vol. 35, no. 4, pp. 1222-1233, 2015.

[127] Y. Cheng, J. Y. Mai, M. F. Wang, G. F. Chen, and J. Ping, "Antifibrotic effect of total flavonoids of Astmgali Radix on dimethylnitrosamine-induced liver cirrhosis in rats," Chinese Journal of Integrative Medicine, vol. 23, no. 1, pp. 48-54, 2017.

[128] T. W. Kensler, G. S. Qian, J. G. Chen, and J. D. Groopman, "Translational strategies for cancer prevention in liver," Nature Reviews Cancer, vol. 3, no. 5, pp. 321-329, 2003.

[129] M. A. Mutalib, F. Ali, F. Othman, R. Ramasamy, and A. Rahmat, "Phenolics profile and anti-proliferative activity of Cyphomandra Betacea fruit in breast and liver cancer cells," SpringerPlus, vol. 5, no. 1, p. 2105, 2016.

[130] X. Lin, J. Wei, Y. Chen et al., "Isoorientin from Gypsophila elegans induces apoptosis in liver cancer cells via mitochondrial-mediated pathway," Journal of Ethnopharmacology, vol. 187, pp. 187-194, 2016.

[131] Y. L. Hsu, M. F. Hou, E. M. Tsai, and P. L. Kuo, "Tricetin, a dietary flavonoid, induces apoptosis through the reactive oxygen species/c-Jun NH2-terminal kinase pathway in human liver cancer cells," Journal of Agricultural and Food Chemistry, vol. 58, no. 23, pp. 12547-12556, 2010.

[132] Y. Zhang, W. Duan, L. Owusu, D. Wu, and Y. Xin, "Epigallocatechin-3-gallate induces the apoptosis of hepatocellular carcinoma LM6 cells but not non-cancerous liver cells," International Journal of Molecular Medicine, vol. 35, no. 1, pp. 117-124, 2015.

[133] H. Ali, S. Dixit, D. Ali et al., "Isolation and evaluation of biological efficacy of quercetol in human hepatic carcinoma cells," Drug Design, Development and Therapy, vol. 10, pp. 155-162, 2016.

[134] Y. F. Wang, T. Li, Z. H. Tang et al., "Baicalein triggers autophagy and inhibits the protein kinase $\mathrm{B} /$ mammalian target of rapamycin pathway in hepatocellular carcinoma HepG2 cells," Phytotherapy Research, vol. 29, no. 5, pp. 674-679, 2015.

[135] R. R. Liang, S. Zhang, J. A. Qi et al., "Preferential inhibition of hepatocellular carcinoma by the flavonoid Baicalein through blocking MEK-ERK signaling," International Journal of Oncology, vol. 41, no. 3, pp. 969-978, 2012.

[136] M. Zou, N. Lu, C. Hu et al., "Beclin 1-mediated autophagy in hepatocellular carcinoma cells: implication in anticancer efficiency of oroxylin a via inhibition of mTOR signaling," Cellular Signalling, vol. 24, no. 8, pp. 1722-1732, 2012.

[137] M. Xu, N. Lu, Z. Sun et al., "Activation of the unfolded protein response contributed to the selective cytotoxicity of oroxylin A in human hepatocellular carcinoma HepG2 cells," Toxicology Letters, vol. 212, no. 2, pp. 113-125, 2012.

[138] T. Nishikawa, T. Nakajima, M. Moriguchi et al., "A green tea polyphenol, epigalocatechin-3-gallate, induces apoptosis of human hepatocellular carcinoma, possibly through inhibition of Bcl-2 family proteins," Journal of Hepatology, vol. 44, no. 6, pp. 1074-1082, 2006. 
[139] M. Shimizu, Y. Shirakami, H. Sakai et al., "EGCG inhibits activation of the insulin-like growth factor (IGF)/IGF-1 receptor axis in human hepatocellular carcinoma cells," Cancer Letters, vol. 262, no. 1, pp. 10-18, 2008.

[140] X. Shen, Y. Zhang, Y. Feng et al., "Epigallocatechin-3-gallate inhibits cell growth, induces apoptosis and causes $S$ phase arrest in hepatocellular carcinoma by suppressing the AKT pathway," International Journal of Oncology, vol. 44, no. 3, pp. 791-796, 2014.

[141] M. Youns and W. Abdel Halim Hegazy, "The natural flavonoid Fisetin inhibits cellular proliferation of hepatic, colorectal, and pancreatic cancer cells through modulation of multiple signaling pathways," PLoS One, vol. 12, no. 1, article e0169335, 2017.

[142] H. Jiang, D. Wu, D. Xu et al., "Eupafolin exhibits potent anti-angiogenic and antitumor activity in hepatocellular carcinoma," International Journal of Biological Sciences, vol. 13, no. 6, pp. 701-711, 2017.

[143] L. Gao, L. Wang, Z. Sun et al., "Morusin shows potent antitumor activity for human hepatocellular carcinoma in vitro and in vivo through apoptosis induction and angiogenesis inhibition," Drug Design, Development and Therapy, vol. 11, pp. 1789-1802, 2017.

[144] V. Sivaramakrishnan and S. Niranjali Devaraj, "Morin regulates the expression of NF- $\kappa \mathrm{B}-\mathrm{p} 65$, COX-2 and matrix metalloproteinases in diethylnitrosamine induced rat hepatocellular carcinoma," Chemico-Biological Interactions, vol. 180, no. 3, pp. 353-359, 2009.

[145] H. B. Yu, H. F. Zhang, X. Zhang et al., "Resveratrol inhibits VEGF expression of human hepatocellular carcinoma cells through a NF-kappa B-mediated mechanism," Hepato-Gastroenterology, vol. 57, no. 102-103, pp. 1241-1246, 2010.

[146] S. Sur, D. Pal, R. Roy et al., "Tea polyphenols EGCG and TF restrict tongue and liver carcinogenesis simultaneously induced by $\mathrm{N}$-nitrosodiethylamine in mice," Toxicology and Applied Pharmacology, vol. 300, pp. 34-46, 2016.

[147] S. Sur, D. Pal, S. Mandal, A. Roy, and C. K. Panda, “Tea polyphenols epigallocatechin gallete and theaflavin restrict mouse liver carcinogenesis through modulation of self-renewal Wnt and hedgehog pathways," The Journal of Nutritional Biochemistry, vol. 27, pp. 32-42, 2016.

[148] X. Song, S. Yin, E. Zhang et al., "Glycycoumarin exerts anti-liver cancer activity by directly targeting T-LAK celloriginated protein kinase," Oncotarget, vol. 7, no. 40, pp. 65732-65743, 2016.

[149] L. Yuan, J. Wang, W. Wu, Q. Liu, and X. Liu, "Effect of isoorientin on intracellular antioxidant defence mechanisms in hepatoma and liver cell lines," Biomedicine \& Pharmacotherapy, vol. 81, pp. 356-362, 2016.

[150] H. Dong, W. Lin, J. Wu, and T. Chen, "Flavonoids activate pregnane $\mathrm{x}$ receptor-mediated CYP $3 A 4$ gene expression by inhibiting cyclin-dependent kinases in HepG2 liver carcinoma cells," BMC Biochemistry, vol. 11, no. 1, p. 23, 2010.

[151] Y. Yan, J. Li, J. Han, N. Hou, Y. Song, and L. Dong, "Chlorogenic acid enhances the effects of 5-fluorouracil in human hepatocellular carcinoma cells through the inhibition of extracellular signal-regulated kinases," Anti-Cancer Drugs, vol. 26, no. 5, pp. 540-546, 2015.

[152] G. Liang, A. Tang, X. Lin et al., "Green tea catechins augment the antitumor activity of doxorubicin in an in vivo mouse model for chemoresistant liver cancer," International Journal of Oncology, vol. 37, no. 1, pp. 111-123, 2010.
[153] J. D. He, Z. Wang, S. P. Li et al., "Vitexin suppresses autophagy to induce apoptosis in hepatocellular carcinoma via activation of the JNK signaling pathway," Oncotarget, vol. 7, no. 51, pp. 84520-84532, 2016.

[154] C. Chen, L. Wang, R. Wang et al., "Phenolic contents, cellular antioxidant activity and antiproliferative capacity of different varieties of oats," Food Chemistry, vol. 239, pp. 260-267, 2018.

[155] C. Huang, Y. X. Wei, M. C. Shen, Y. H. Tu, C. C. Wang, and H. C. Huang, "Chrysin, abundant in morinda citrifolia fruit water-EtOAc extracts, combined with apigenin synergistically induced apoptosis and inhibited migration in human breast and liver cancer cells," Journal of Agricultural and Food Chemistry, vol. 64, no. 21, pp. 4235-4245, 2016.

[156] Y. J. Hwang, E. J. Lee, H. R. Kim, and K. A. Hwang, "Molecular mechanisms of luteolin-7-O-glucoside-induced growth inhibition on human liver cancer cells: G2/M cell cycle arrest and caspase-independent apoptotic signaling pathways," BMB Reports, vol. 46, no. 12, pp. 611-616, 2013.

[157] M. Xu, N. Lu, H. Zhang et al., "Wogonin induced cytotoxicity in human hepatocellular carcinoma cells by activation of unfolded protein response and inactivation of AKT," Нераtology Research, vol. 43, no. 8, pp. 890-905, 2013.

[158] F. Wang, Y. H. Wang, J. J. Wang, H. L. Xu, and C. M. Wang, "Eriodictyol-induced anti-cancer and apoptotic effects in human hepatocellular carcinoma cells are associated with cell cycle arrest and modulation of apoptosis-related proteins," Bangladesh Journal of Pharmacology, vol. 11, no. 2, pp. 285291, 2016.

[159] R. Banjerdpongchai, B. Wudtiwai, P. Khaw-on, W. Rachakhom, N. Duangnil, and P. Kongtawelert, "Hesperidin from citrus seed induces human hepatocellular carcinoma HepG2 cell apoptosis via both mitochondrial and death receptor pathways," Tumour Biology, vol. 37, no. 1, pp. 227-237, 2016.

[160] J. Zhang, J. Song, D. Wu, J. Wang, and W. Dong, "Hesperetin induces the apoptosis of hepatocellular carcinoma cells via mitochondrial pathway mediated by the increased intracellular reactive oxygen species, ATP and calcium," Medical Oncology, vol. 32, no. 4, p. 101, 2015.

[161] W. G. Zhang, X. C. Yin, X. F. Liu et al., "Puerarin induces hepatocellular carcinoma cell apoptosis modulated by MAPK signaling pathways in a dose-dependent manner," Anticancer Research, vol. 37, no. 8, pp. 4425-4431, 2017.

[162] H. T. Zhang, H. Luo, J. Wu et al., "Galangin induces apoptosis of hepatocellular carcinoma cells via the mitochondrial pathway," World Journal of Gastroenterology, vol. 16, no. 27, pp. 3377-3384, 2010.

[163] L. Su, X. Chen, J. Wu et al., "Galangin inhibits proliferation of hepatocellular carcinoma cells by inducing endoplasmic reticulum stress," Food and Chemical Toxicology, vol. 62, pp. 810-816, 2013.

[164] X. Huang, T. Lian, X. Guan et al., "Dihydromyricetin reduces TGF- $\beta$ via P53 activation-dependent mechanism in hepatocellular carcinoma HepG2 cells," Protein \& Peptide Letters, vol. 24, no. 5, pp. 419-424, 2017.

[165] D. Wang, Q. Sun, J. Wu et al., “A new prenylated flavonoid induces G0/G1 arrest and apoptosis through p38/JNK MAPK pathways in human hepatocellular carcinoma cells," Scientific Reports, vol. 7, no. 1, article 5736, 2017.

[166] G. Shu, J. Yang, W. Zhao et al., "Kurarinol induces hepatocellular carcinoma cell apoptosis through suppressing cellular 
signal transducer and activator of transcription 3 signaling," Toxicology and Applied Pharmacology, vol. 281, no. 2, pp. 157-165, 2014.

[167] Z. Wang, H. Zhang, J. Zhou et al., "Eriocitrin from lemon suppresses the proliferation of human hepatocellular carcinoma cells through inducing apoptosis and arresting cell cycle," Cancer Chemotherapy and Pharmacology, vol. 78, no. 6, pp. 1143-1150, 2016.

[168] G. Huang, B. Tang, K. Tang et al., "Isoquercitrin inhibits the progression of liver cancer in vivo and in vitro via the MAPK signalling pathway," Oncology Reports, vol. 31, no. 5, pp. 2377-2384, 2014.

[169] H. Chen, Y. Huang, J. Huang, L. Lin, and G. Wei, “Gigantol attenuates the proliferation of human liver cancer HepG2 cells through the PI $3 \mathrm{~K} / \mathrm{Akt} / \mathrm{NF}-\kappa \mathrm{B}$ signaling pathway," Oncology Reports, vol. 37, no. 2, pp. 865-870, 2017.

[170] A. Y. Choi, J. H. Choi, K. Y. Hwang et al., "Licochalcone a induces apoptosis through endoplasmic reticulum stress via a phospholipase $\mathrm{C} \gamma 1-, \mathrm{Ca}^{2+}$, , and reactive oxygen speciesdependent pathway in HepG2 human hepatocellular carcinoma cells," Apoptosis, vol. 19, no. 4, pp. 682-697, 2014.

[171] D. H. Go, Y. G. Lee, D. H. Lee et al., "3-decylcatechol induces autophagy-mediated cell death through the IRE1 $\alpha / \mathrm{JNK} / \mathrm{p} 62$ in hepatocellular carcinoma cells," Oncotarget, vol. 8, no. 35, pp. 58790-58800, 2017.

[172] Y. J. Zhang, H. Xiang, J. S. Liu, D. Li, Z. Y. Fang, and H. Zhang, "Study on the mechanism of AMPK signaling pathway and its effect on apoptosis of human hepatocellular carcinoma SMMC-7721 cells by curcumin," European Review for Medical and Pharmacological Sciences, vol. 21, no. 5, pp. 1144-1150, 2017.

[173] Z. Liu, B. Ren, Y. Wang et al., "Sesamol induces human hepatocellular carcinoma cells apoptosis by impairing mitochondrial function and suppressing autophagy," Scientific Reports, vol. 7, article 45728, 2017.

[174] X. Cheng, F. Zhong, K. He, S. Sun, H. Chen, and J. Zhou, "EHHM, a novel phenolic natural product from Livistona chinensis, induces autophagy-related apoptosis in hepatocellular carcinoma cells," Oncology Letters, vol. 12, no. 5, pp. 3739-3748, 2016.

[175] Y. Yan, N. Liu, N. Hou, L. Dong, and J. Li, "Chlorogenic acid inhibits hepatocellular carcinoma in vitro and in vivo," The Journal of Nutritional Biochemistry, vol. 46, pp. 68-73, 2017.

[176] S. Jagan, G. Ramakrishnan, P. Anandakumar, S. Kamaraj, and T. Devaki, "Antiproliferative potential of gallic acid against diethylnitrosamine-induced rat hepatocellular carcinoma," Molecular and Cellular Biochemistry, vol. 319, no. 1-2, pp. 51-59, 2008.

[177] F. Yang, J. Li, J. Zhu, D. Wang, S. Chen, and X. Bai, "Hydroxysafflor yellow A inhibits angiogenesis of hepatocellular carcinoma via blocking ERK/MAPK and NF- $\kappa \mathrm{B}$ signaling pathway in H22 tumor-bearing mice," European Journal of Pharmacology, vol. 754, pp. 105-114, 2015.

[178] K. H. Lee, M. H. Yeh, S. T. Kao et al., "The inhibitory effect of hesperidin on tumor cell invasiveness occurs via suppression of activator protein 1 and nuclear factor-kappaB in human hepatocellular carcinoma cells," Toxicology Letters, vol. 194, no. 1-2, pp. 42-49, 2010.

[179] M. H. Yeh, S. T. Kao, C. M. Hung, C. J. Liu, K. H. Lee, and C. C. Yeh, "Hesperidin inhibited acetaldehyde-induced matrix metalloproteinase-9 gene expression in human hepatocellular carcinoma cells," Toxicology Letters, vol. 184, no. 3, pp. 204-210, 2009.

[180] H. R. Yen, C. J. Liu, and C. C. Yeh, "Naringenin suppresses TPA-induced tumor invasion by suppressing multiple signal transduction pathways in human hepatocellular carcinoma cells," Chemico-Biological Interactions, vol. 235, pp. 1-9, 2015.

[181] S. H. Fan, Y. Y. Wang, J. Lu et al., "Luteoloside suppresses proliferation and metastasis of hepatocellular carcinoma cells by inhibition of NLRP3 inflammasome," PLoS One, vol. 9, no. 2, article e89961, 2014.

[182] X. Liu, S. Tian, M. Liu, L. Jian, and L. Zhao, "Wogonin inhibits the proliferation and invasion, and induces the apoptosis of HepG2 and Bel7402 HCC cells through NF $\kappa \mathrm{B} /$ Bcl-2, EGFR and EGFR downstream ERK/AKT signaling," International Journal of Molecular Medicine, vol. 38, no. 4, pp. 1250-1256, 2016.

[183] S. T. Chien, M. D. Shi, Y. C. Lee, C. C. Te, and Y. W. Shih, "Galangin, a novel dietary flavonoid, attenuates metastatic feature via PKC/ERK signaling pathway in TPA-treated liver cancer HepG2 cells," Cancer Cell International, vol. 15, no. 1, p. $15,2015$.

[184] M. A. Zapf, A. N. Kothari, C. E. Weber et al., "Green tea component epigallocatechin-3-gallate decreases expression of osteopontin via a decrease in mRNA half-life in cell lines of metastatic hepatocellular carcinoma," Surgery, vol. 158, no. 4, pp. 1039-1048, 2015.

[185] W. Dai, F. Wang, L. He et al., "Genistein inhibits hepatocellular carcinoma cell migration by reversing the epithelial-mesenchymal transition: partial mediation by the transcription factor $\mathrm{NFAT}_{1}$," Molecular Carcinogenesis, vol. 54, no. 4, pp. 301-311, 2015.

[186] H. Yu, C. Pan, S. Zhao, Z. Wang, H. Zhang, and W. Wu, "Resveratrol inhibits tumor necrosis factor- $\alpha$-mediated matrix metalloproteinase- 9 expression and invasion of human hepatocellular carcinoma cells," Biomedicine \& Pharmacotherapy, vol. 62, no. 6, pp. 366-372, 2008.

[187] F. Gao, G. Deng, W. Liu, K. Zhou, and M. Li, "Resveratrol suppresses human hepatocellular carcinoma via targeting HGF-c-Met signaling pathway," Oncology Reports, vol. 37, no. 2, pp. 1203-1211, 2017.

[188] J. Shao, Q. Meng, and Y. Li, “Theaflavins suppress tumor growth and metastasis via the blockage of the STAT3 pathway in hepatocellular carcinoma," OncoTargets and Therapy, vol. 9, pp. 4265-4275, 2016.

[189] T. Pei, Q. Meng, J. Han et al., “(-)-Oleocanthal inhibits growth and metastasis by blocking activation of STAT3 in human hepatocellular carcinoma," Oncotarget, vol. 7, no. 28, pp. 43475-43491, 2016.

[190] A. K. Maurya and M. Vinayak, "Anticarcinogenic action of quercetin by downregulation of phosphatidylinositol 3kinase (PI3K) and protein kinase C (PKC) via induction of p53 in hepatocellular carcinoma (HepG2) cell line," Molecular Biology Reports, vol. 42, no. 9, pp. 1419-1429, 2015.

[191] S. C. Iyer, A. Gopal, and D. Halagowder, "Myricetin induces apoptosis by inhibiting P21 activated kinase 1 (PAK1) signaling cascade in hepatocellular carcinoma," Molecular and Cellular Biochemistry, vol. 407, no. 1-2, pp. 223-237, 2015.

[192] R. H. Hussein and F. K. Khalifa, "The protective role of ellagitannins flavonoids pretreatment against $\mathrm{N}$ nitrosodiethylamine induced-hepatocellular carcinoma," 
Saudi Journal of Biological Sciences, vol. 21, no. 6, pp. 589-596, 2014.

[193] P. W. Zhang, F. X. Chen, D. Li, W. H. Ling, and H. H. Guo, "A CONSORT-compliant, randomized, double-blind, placebo-controlled pilot trial of purified anthocyanin in patients with nonalcoholic fatty liver disease," Medicine, vol. 94, no. 20, article e758, 2015.

[194] S. Chen, X. Zhao, J. Wan et al., "Dihydromyricetin improves glucose and lipid metabolism and exerts anti-inflammatory effects in nonalcoholic fatty liver disease: a randomized controlled trial," Pharmacological Research, vol. 99, pp. 74-81, 2015.

[195] R. Sakata, T. Nakamura, T. Torimura, T. Ueno, and M. Sata, "Green tea with high-density catechins improves liver function and fat infiltration in non-alcoholic fatty liver disease (NAFLD) patients: a double-blind placebo-controlled study," International Journal of Molecular Medicine, vol. 32, no. 5, pp. 989-994, 2013.

[196] S. Chen, X. Zhao, L. Ran et al., "Resveratrol improves insulin resistance, glucose and lipid metabolism in patients with non-alcoholic fatty liver disease: a randomized controlled trial," Digestive and Liver Disease, vol. 47, no. 3, pp. 226232, 2015.

[197] S. Dash, C. Xiao, C. Morgantini, L. Szeto, and G. F. Lewis, "High-dose resveratrol treatment for 2 weeks inhibits intestinal and hepatic lipoprotein production in overweight/obese men," Arteriosclerosis, Thrombosis, and Vascular Biology, vol. 33, no. 12, pp. 2895-2901, 2013.

[198] V. S. Chachay, G. A. Macdonald, J. H. Martin et al., "Resveratrol does not benefit patients with nonalcoholic fatty liver disease," Clinical Gastroenterology and Hepatology, vol. 12, no. 12, pp. 2092-2103.e6, 2014.

[199] D. Gonçalves, C. Lima, P. Ferreira et al., "Orange juice as dietary source of antioxidants for patients with hepatitis C under antiviral therapy," Food \& Nutrition Research, vol. 61, no. 1, article 1296675, 2017. 


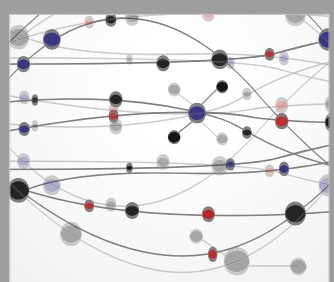

The Scientific World Journal
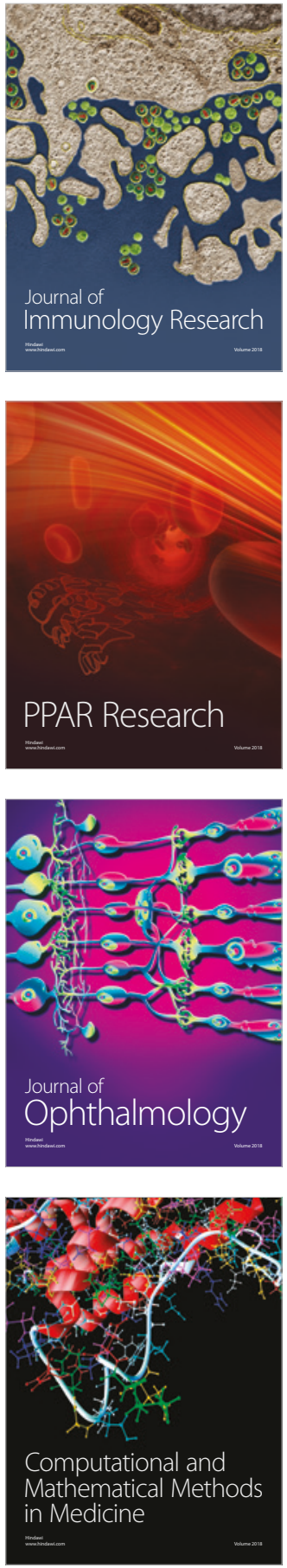

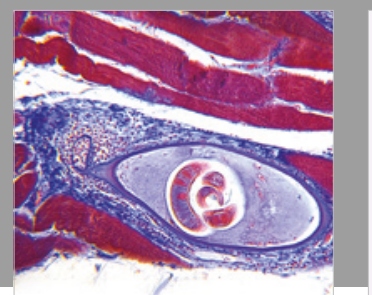

Gastroenterology Research and Practice

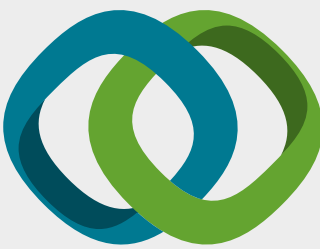

\section{Hindawi}

Submit your manuscripts at

www.hindawi.com
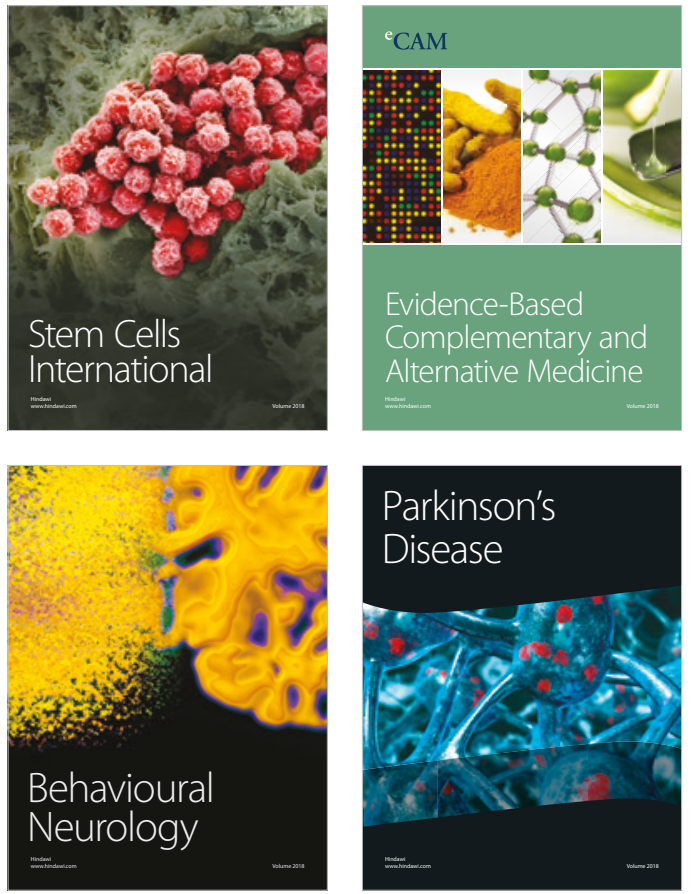

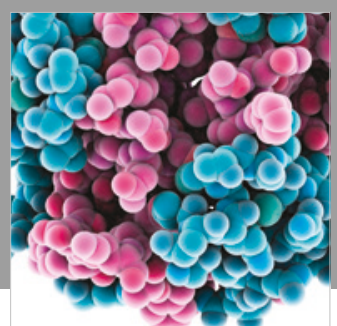

ournal of

Diabetes Research

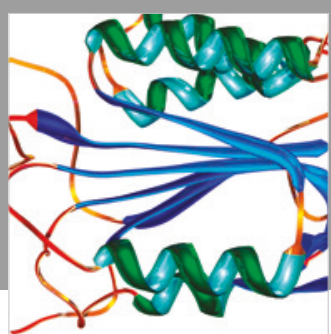

Disease Markers
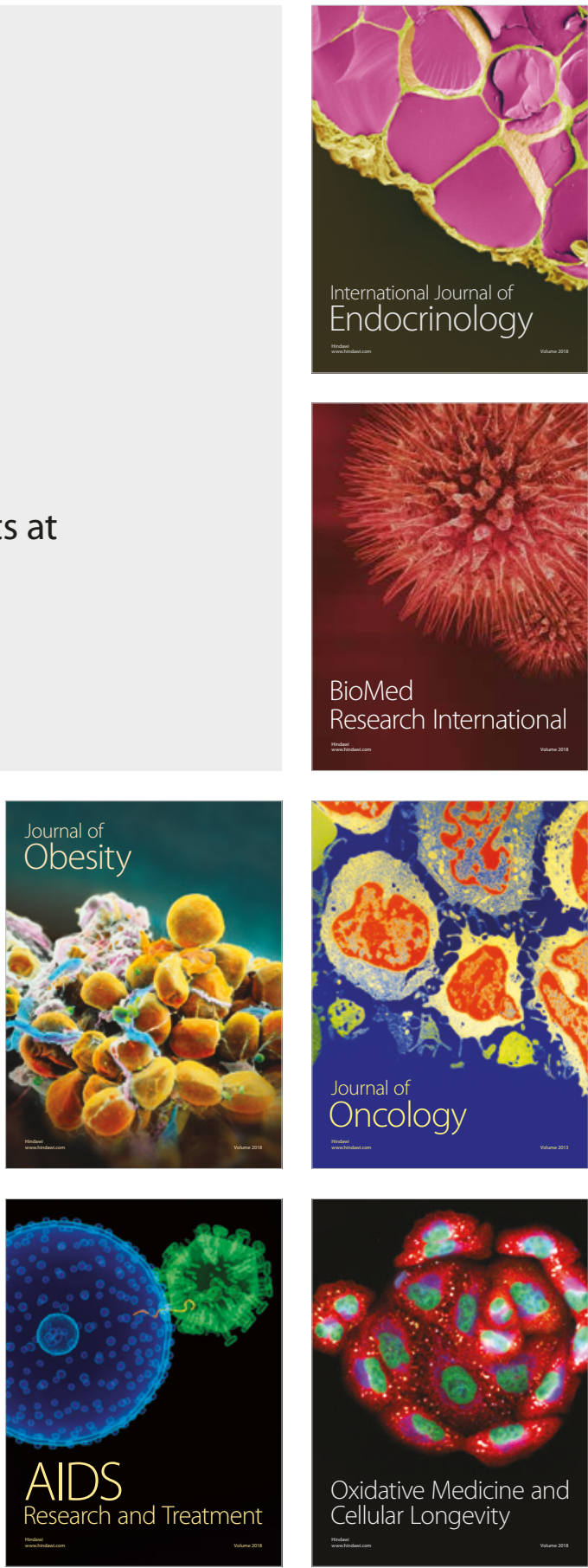